Expanding the search for emerging mental ill health

to safeguard student potential and vocational success in high school - a narrative review

Authors

1. Siann Bowman, Department of Occupational Therapy, School of Allied Health, LaTrobe University Melbourne Australia.

2. Dr Carol McKinstry, Department of Occupational Therapy, LaTrobe Rural Health School, LaTrobe University Melbourne Australia.

3. Dr Linsey Howie, Department of Occupational Therapy, School of Clinical and Community Allied Health, LaTrobe University Melbourne Australia.

4. Professor Patrick McGorry, The National Centre of Excellence in Youth Mental Health, Orygen. The University of Melbourne.

Key Words: at risk mental state, clinical staging model, high school, school dropout Corresponding Author: Siann Bowman s.bowman@latrobe.edu.au

Department of Occupational Therapy, School of Allied Health, LaTrobe University Melbourne Australia.

This is the author manuscript accepted for publication and has undergone full peer review but has not been through the copyediting, typesetting, pagination and proofreading process, which may lead to differences between this version and the Version of Record. Please cite this article as doi: 10.1111/eip.12928

This article is protected by copyright. All rights reserved. 


\title{
ABSTRACT \\ Expanding the search for emerging mental ill health to safeguard student potential and vocational success in high school - a narrative review
}

\begin{abstract}
-
Aim -Young people experiencing mental ill health are more likely than their healthy aged peers to drop out of high school. This can result in social exclusion and vocational derailment. Identifying young people at risk and taking action before an illness is established or school dropout occurs is an important goal. This study aimed to examine evidence for the risk markers and at risk mental states of the clinical staging model (Stage $0-1 b$ ), and whether these risk states and early symptoms impact school participation and academic attainment.
\end{abstract}

Method - This narrative review assembles research from both the psychiatry and education literature. It examines Stage 0 to Stage $1 \mathrm{~b}$ of the clinical staging model and links the risk states and early symptoms to evidence about the academic success of young people in high school.

Results - In accordance with the clinical staging model and evidence from education literature, childhood trauma and parental mental illness can impact school engagement and academic progress. Sleep disturbance can result in academic failure. Undifferentiated depression and anxiety can increase the risk for school dropout. Subthreshold psychosis and hypomanic states are associated with functional impairment and high rates of NEET but are not recognised in the education literature.

This article is protected by copyright. All rights reserved. 
Conclusion - Risk markers for emerging mental ill health can be identified in education research and demonstrate an impact on a student's success in high school. Clear referral protocols need to be embedded into school life to reduce risk of progression to later stages of illness and support school participation and success.

Key Words: at risk mental state, ultra high risk, clinical high risk, clinical staging, high school 


\section{INTRODUCTION}

Young people on the threshold of adult life have hopes and dreams and seek a meaningful and contributing life. The greatest threat to this is mental ill health that typically occurs when the educational building blocks of a future working life are assembled. Mental ill health has a significant impact on developmental trajectories of young people and contributes to the global economic burden of non-communicable disease (Bloom, 2011; Patel, 2007). Identifying young people at risk of developing mental illness and taking action before the illness is established is therefore an important goal. There is little acknowledgement in the literature about emerging mental ill health and the academic success of young people. There is however evidence in the education literature about the individual factors that negatively impact high school participation and achievement. These two areas of research are not often brought together, which is problematic because they both aim to improve outcomes for young people and overlap in their findings in terms of risk factors for poor functional performance.

Adolescence and early adulthood are the peak periods for the onset of most mental illnesses, with up to 75\% emerging before the age of 25 (Kessler, 2005, 2007). Half of all lifetime cases of mental illness are apparent by the age of 14 (ABS, 2008, AIHW, 2011). In Australia, one in every five adolescents is likely to experience clinical depression by the age of 18 (ABS, 2008; Birmaher, 1996; Kessler, 2005; Lewisohn, 1993). Anxiety and depression are the leading contributors to the burden of disease for young Australians (AIHW, 2011). The most common anxiety disorders are social anxiety and posttraumatic stress disorder, with half experiencing their first symptoms by the age of 11 (AIHW, 2011; Kessler, 2007). 
Psychotic disorders are the third leading contributor to the burden of disease in Australian males aged 15-24 and the fifth leading contributor for females (ABS, 2008; AIHW, 2011; Jeblensky, 1999). Substance use disorders in young people aged 16-24 is estimated to be 12.7\% (AIHW, 2011). These findings lead to calls for identification and safe interventions to be delivered as early as possible to avoid illness progression and improve functional outcomes_(McGorry, 2010). In response to this challenge and the low level of service use by young people, a developing network of primary level early intervention mental health services for individuals aged 12 to 25 has been established across Australia—called “headspace” (Rickwood, 2013). This Australian program is just one example of international innovations in youth mental health care with others established in the USA, UK and Ireland (McFarlane, 2010; McGorry, 2013).

Adolescents spend more time in school than in any other formal institution, and schools offer an essential pillar in the scaffolding necessary for adolescents' transition to adulthood (Arnett, 2010; Rutter, 1979). Schools play a key part in a young person’s development, including peer relationships, identity formation, knowledge acquisition, academic progress, emotional control and physical and moral development (Arnett, 2010). These areas are all impacted by mental ill health (Cross, 2014). Young people, who do not finish school due to mental ill health, experience a greater likelihood of low self-esteem and fragile identity, social exclusion, functional disability and vocational derailment (Goulding, 2010; Isohanni, 1998; McGorry, 2013; Stein, 2012).

Young people who leave high school prematurely and are without a job are described in policy circles as “NEET”’ (Not in Employment, Education, or Training) (OECD, 2012). 
Those who are NEET early on in life are more likely to be NEET later in life, indicating a higher risk of chronic unemployment and socio-economic disadvantage (Franzen, 2005; National Statistics of the United Kingdom, 2010; Quintini, 2007). One of the risk factors associated with NEET status is low academic achievement (National Statistics of the United Kingdom, 2010; O’Dea, 2016; Quintini, 2007). 'Days spent out of role’, is another measure of inability to carry out day to day activities and has been used worldwide as a measure of impact (ACOEM, 2009; Davis, 2005; Loeppke, 2009). Days spent out of role due to mental illness is a major source of lost human capital across the world (Alonso et al., 2011; Merikangas, 2007; Suhrcke, 2008; ). The high proportion of adolescents presenting as NEET and 'out of role' to headspace suggests that these early intervention services are, in many cases, not delivered early enough (O’Dea, 2016).

Prospective Australian, European, American and Mexican studies show that disengagement from high school often occurs for young people experiencing mental ill health (Benjet, 2012; Cross, 2014; Eurofound, 2012; McGorry, 2013; Stein, 2012). In an Australian National Survey of Psychosis, 68\% of participants had not finished high school $(\mathrm{n}=1825)$ (Waghorn, 2012). Recent studies with first episode psychosis (FEP) populations also indicate that over 50\% have less than 10 years of education (Bowman, 2017). The pattern is also similar for other complex and potentially severe mental illnesses such as major mood disorders, anxiety disorders, eating disorders and borderline personality disorder with prospective international evidence (Australia, Canada, China, Finland, India, Mexica, Netherlands and New Zealand) demonstrating that $46 \%$ of school dropout is attributed to these disorders (Riglin, 2013). Finishing high school can clearly be difficult for young people 
experiencing mental ill health and they are more likely than their healthy aged peers to drop out of school (Leach, 2012; Riglin, 2013, 2014; Waghorn, 2012).

Research from Canada, Australia, America and the UK has identified common risk markers for the development of mental ill health and these include sleep disturbance, childhood trauma, having a family member with serious mental illness, poor psychosocial functioning, substance use, anxiety and depression (Addington, 2017; Amminger, 2006; Cannon, 2008; Davey, 2019; Fusar-Poli, 2014; Grierson, 2017; Hartmann, 2017, 2018; Kendler, 2014; Kraan, 2015; McGorry, 2007, 2010, 2013, 2014; Thompson, 2009, 2011; Velthorst, 2010; Yung, 2004). These often undifferentiated symptoms can progress to subthreshold states of psychosis, bipolar and moderate depression alongside functional decline (Hartmann, 2018; McGorry, 2018). In the early stages of mental ill health, diffuse and unstable subthreshold states of anxiety and depression are common, often commingled with psychotic-like disturbances and emotional dysregulation, to produce a series of phenotypes (Hickie, 2013; McGorry, 2016, 2013, 2018; van Os, 2017). A serious treatment gap exists with only a minority of young people being able to access quality care when these symptoms arise. The problem of identifying emerging mental ill health and delivering effective treatment is an urgent issue.

The at risk/clinical high risk/ultra high risk (UHR) concept originated from the knowledge that psychosis is preceded by subthreshold symptoms of insufficient severity and clarity to justify a diagnosis but there is still a need for care (McGorry, 2013, 2014, 2018, Hartmann, 2018). This resulted in the conceptualisation of the prodromal period as an "at risk mental state.” The "at risk mental state” for psychosis research paradigm has illuminated the 
risk factors involved in psychosis onset, the limitations of diagnostic systems and risk identification approaches, the diffuse and unstable symptom patterns in early stages, and their potential transdiagnostic trajectories (Hartmann, 2018; McGorry, 2018).

It has become increasingly evident that the "at risk mental state” (ARMS) status extends beyond risk of transition to psychosis (McGorry 2018; McHugh, 2018; Nelson, 2018; Yung, 2017). Most individuals who meet criteria will not develop a psychotic disorder but will experience poor psychosocial functioning (de Wit, 2014; Nelson, 2013; Rutigliano, 2016; Simon, 2011). Progression to persistent mood, anxiety, personality and/or substance use disorders is a very common outcome, as is suicide risk (Fusar-Poli, 2014; Lin, 2015; Rutigliano, 2016). Hence, extending the boundary beyond psychosis is essential (de Wit, 2014; Lin, 2015; Rutigliano, 2016). In addition, it is recognised that the "at risk mental state" should be a syndrome in its own right as well as a risk marker for disorder progression (McGorry, 2018; Polari, 2018). Such findings have driven a reframing of “at risk mental state” (ARMS) as a clinical state signifying transdiagnostic risk and need for clinical care (McGorry, 2006; McGorry, 2016; Yung, 2012; van Os, 2017). Henceforth throughout the paper ARMS will refer to this definition.

The clinical staging model developed by McGorry, Hickie and colleagues adapts the ARMS approach to encompass a collection of syndromes within a single 'transdiagnostic 'model (one non-clinical and four clinical stages) (Hickie et al., 2013; McGorry et al., 2006). Early clinical stages are characterised by phenotypes that are milder in symptom severity, lack specific or fully formed syndromal features and are associated with less impairment. Later stages are characterised by more severe symptom, functional impairment and clear 
evidence of stability, persistence or reoccurrence (Cross et al., 2014; Hickie et al., 2013, McGorry, 2019) (Table 1).

The model proposes that the emergence of earlier stages of mental ill health represents a modifiable risk of progression to later and more serious stages of illness (Cross, 2014; Hartmann, 2017, 2018; McGorry, 2007, 2013, 2014, 2018). Disorder states are defined according to stages, ranging from a pre-symptomatic at-risk stage (stage $0=$ family history of mental illness, history of trauma), to undifferentiated general symptoms (stage $1 \mathrm{a}=$ e.g. sleep disturbance, anxiety, depression, help seeking with distress; mild functional decline), to moderate and more specific symptoms alongside functional decline (stage $1 \mathrm{~b}=$ attenuated psychotic symptoms, subthreshold bipolar states, moderate depression) (Cross, 2014; Hartmann, 2017, 2018; McGorry, 2007, 2013; 2010; 2014, 2018). Further stages include fullthreshold (stage 2), more persistent (stage 3), and severe, unremitted illness (stage 4) (McGorry, 2007, 2013; 2010; 2014, 2018) (Figure 1).

Randomized control trials conducted in Australia, Austria and the UK demonstrate that early detection and intervention provided for individuals experiencing ARMS could prevent the onset of a fully-fledged disorder and promote improved functioning (Yung, 2007, 2011, 2017). Education research demonstrates that mental ill health in high school students is a growing problem significantly impacting participation, educational outcomes and is a major concern for school staff (Dewald, 2010; Farahati, 2003; Garvik, 2013; Overstreet, 2011; Perfect, 2016; Taras, 2015). This narrative review aims to examine the identified risk markers (Stage 0) for the development of mental ill health, and the at risk mental states identified in Stage 1a and 1b of the clinical staging model (Hartmann et al., 2017; 2018; McGorry, 2007; 
2010; 2013; 2014). They have been studied in ARMS samples but not specifically in terms of their impact on school functioning. Characteristics of Stage 0 and $1 \mathrm{a}$ are however identified in the education literature for their negative impact on high school participation and educational success. This review therefore examined evidence from both the youth mental health and the education research specifically related to high school. In accordance with The International Standard Classification of Education (ISCED), this includes levels 2 and 3 (lower and upper secondary education) (ISCED, 2011).

\section{METHOD}

Narrative reviews have been considered by scholars (e.g. Grant, 2009) to be a review in which an empirical lens comparing diverse bodies of work can enable "conceptual innovation" to form a hypothesis, serving as a subsequent "launch pad” for further research (p.93). Baumeister and Leary (1977) proposed that narrative reviews are useful when trying to link a number of studies on different topics together to enable interconnection or reinterpretation to occur. These authors proposed the purpose for narrative reviews is to develop a theory. Common limitations of narrative reviews are they tend to report on the conclusions of the study rather than providing an adequate description of the research design and results, and lack critical appraisal of the evidence.

The overarching goal of this review is to present an argument that the characteristics of ARMS may impact academic performance and participation in high school. It was found that education has not been explored empirically in this population. Considering there was no research specifically reviewing this question in the psychiatric research, the education research was reviewed. It was evident that the characteristics of ARMS Stage 0-1a were 
identified by researchers in education, and they had evaluated their impact on high school performance.

We have aimed to strike a balance between purposeful selection and systematic coverage of the literature to help us best present a case for this review. We focused on identifying the most significant literature with regard to the aims of our paper, rather than producing a comprehensive search using systematic processes. To best capture the current state and quality of the research field studies were not excluded based on quality and therefore all eligible articles were included. Each article was critically evaluated by the first author according to key results, limitations, suitability of methods used to test the initial hypothesis; quality of result obtained; interpretation of results; impact of the conclusions in the field. PRISMA guidelines were followed where possible however given that the current research is a narrative review PRISMA guidelines were largely not applicable.

Searches were conducted and evidence retrieved from the databases CINAHL, MEDLINE, Psych LIT, Psych INFO and Education SAGE from 1995 to 2019 to identify English language peer reviewed articles reporting characteristics of ARMS Clinical Stages 0 - 1b. Articles were included from the education literature that identified these characteristics as impacting high school performance and academic achievement. Please see Table 2 for comprehensive Search Strategy and Figure 2 for Flow Chart of the Literature Selection Process for Review. All citations were imported into endnote, duplicates were detected and subsequently deleted. Titles and abstracts were screened by the first author. All potentially relevant articles were downloaded in full text and reviewed for final inclusion against the eligibility criteria. 
There were no studies specifically investigating the high school participation and academic attainment of individuals with ARMS in Clinical Stages 0-1b. No studies have been conducted with school personnel exploring their understanding and experience of students with ARMS. Education literature demonstrates that the characteristics of Clinical Stages 0-1a can impact high school performance and academic success.

This study aims to answer the following research questions:

1. What are the characteristics of the Clinical Staging Model Stages 0-1b?

2. Is there evidence in the psychiatric literature that these characteristics impact high school performance and academic achievement?

3. Is there evidence in the education literature that these characteristic impact high school performance and academic achievement?

\section{RESULTS}

The characteristics of each clinical stage will now be discussed. Clinical Stage 0 is explored first, then Clinical Stage 1a and then 1b. Within each stage and for each characteristic, the psychiatry research is presented followed by the education research. The psychiatry research demonstrates a focus on prevalence and impact on the young person. The education research focuses on the characteristics that impact high school performance and academic success. Key findings for each Stage and presented in Table 3, 4 and 5.

\section{CLINICAL STAGING MODEL STAGE 0 - ASYMPTOMATIC, AT RISK POPULATIONS}

\section{Childhood trauma and ARMS}

This article is protected by copyright. All rights reserved. 
Childhood trauma is defined in the research as physical, psychological, sexual, emotional abuse or neglect before the age of 17 years (Bechdolf, 2010; Kraan, 2015; Thompson, 2013). This experience results in disruption to child and adolescent development (Gerrity, 2008; Putnam, 2006). International survey studies Germany, New Zealand, USA and The Netherlands demonstrate a significantly high prevalence of childhood trauma for individuals who experience mood and anxiety disorders, substance use disorders, personality disorders, and psychosis (Campbell, 2007; Chapman, 2004; Felitti, 1998; Fernando, 2014; Gibb, 2008; Kessler, 1997; Khan, 2015; Muenzenmaier, 2015; Putman, 2006; Read, 2005; Spinhoven, 2010; Widom, 2007). Epidemiological research, retrospective cohort studies and survey studies from Australia and the USA have demonstrated that sexual abuse specifically is a risk factor for developing post traumatic stress disorder, eating disorders, substance use disorders, suicidal behaviour and psychosis (Al Mamun, 2007; Dube, 2005; Felitti, 1998; Kendler, 2000; Mayo, 2017; Young, 2007). If childhood trauma was entirely removed from the population, the number of people with psychosis would be reduced by a third (Bendall, 2008). Childhood trauma is clearly a risk factor for vulnerability to psychopathology (FusarPoli, 2012; Putnam, 2006; Tunnard, 2014).

Cross-sectional studies and meta-analyses from the USA, Australia, Canada, Turkey, and Finland have found consistently high rates of childhood trauma in ARMS populations when compared to the general population (Addington, 2013; Bechdolf, 2010; Devylder, 2013; Falukozi, 2012; Kline, 2018; Kraan, 2015; Magaud, 2013; Sahin, 2013; Yung, 2015). For example, in the USA, Thompson and colleagues (2009) found in an ARMS sample ( $\mathrm{n}=$ 30), that $97 \%$ had experienced at least one form of trauma - $83 \%$ reported physical abuse, 
$67 \%$ reported emotional abuse, and 27\% sexual abuse. A systematic review and metaanalysis investigating adolescents with ARMS, also found high rates of experienced emotional abuse, physical abuse, and bullying (Peh, 2018). Studies have also investigated whether childhood trauma predicts conversion to psychosis in ARMS samples and sexual trauma was the strongest predictor of transition (Bechdolf, 2010; Thompson, 2013; Varese, 2012). There is no research evidence demonstrating that childhood trauma correlates specifically with negative academic outcomes in ARMS samples as it has not been researched before. The education literature will now be reviewed to ascertain the evidence about childhood trauma and academic performance.

\section{Childhood trauma and high school participation}

International education research from Australia, Brazil, Canada, Colombo, Japan, Palestine, Sweden, UK and USA demonstrates that the neurobiological, cognitive, social and emotional impact of childhood trauma can interfere with school functioning resulting in learning problems, low grades, need for special education, low attendance and increases in problem behaviour (Perfect, 2016; Woodbridge, 2016). Multiple longitudinal and cross sectional studies conducted in the United States, Australia, Israel and the UK have found significant attention, language, memory, processing speed, perceptual reasoning and verbal comprehension problems in high school students who have been exposed to childhood trauma (De Bellis, 2014; DePrince, 2009; Elbert, 2009; Husain, 2016; Kira, 2014; 2012Schoeman, 2009; Trickett, 2011; Viezel, 2015). These cognitive issues result in significantly lower academic ability in reading, English, maths and science as evident in low 
test scores (Delaney-Black, 2002; Duplechain, 2008; Fantuzzo, 2011; Lansford, 2002; McLean, 2013; Overstreet, 2011; Perfect, 2016). Longitudinal studies demonstrate that students who have experienced childhood trauma find it difficult to stay in high school because they find coping with the workload difficult and this negatively impacts engagement and attendance (Lansford, 2002; McLean, 2013; Perzow, 2013; Shonk, 2001). Further, in an American study, high school students who had experienced childhood trauma reported feeling socially excluded, not involved in school activities and not safe in the student -teacher relationship $(\mathrm{n}=149)$ (Perzow, 2013). This resulted in reduced motivation to stay at high school. Findings from cross sectional and qualitative studies from the United States, Sweden, Netherlands and Australia with high school teachers indicate that they observe higher levels of depression, anxiety and social exclusion among students who have experienced childhood trauma compared to those who had not (Daignault, 2009; LamersWinkelman, 2012; Shonk, 2001; Woodbridge, 2016).

\section{Family history of mental illness and ARMS}

A family history of mental illness represents one of the most significant predictors of mental illness in individuals (Kendler, 2005; 2014). Studies over the past four decades have established a strong connection between mental illness of parents and an increased lifetime risk of psychiatric illness for their children ranging from 41\% to 77\% (Kendler, 2005; 2014). Between 21 to $23 \%$ of adolescents in Victoria, Australia have a parent with a mental illness (Maybery, 2009; Reupert, 2013).

This article is protected by copyright. All rights reserved. 
Elevated risk for children has been reported for the whole diagnostic spectrum of parental mental illness such as substance abuse, anxiety disorders, panic disorder, obsessive compulsive disorder, depression, dysthymic disorder, bipolar affective disorder, psychotic disorders, eating disorders, suicide and personality disorders in multiple cross-sectional and longitudinal studies throughout the world (Birmaher, 2009; Black, 2003; Bronisch, 2008; Cannon, 2005; Coolidge, 2001; DelBello, 2001; Lizardi, 2004; Maziade, 2008; Park, 2003; Stowkowy, 2013; Weissman, 2006). The evidence suggests that children of parents with a mental illness have an increased risk of developing the same disorder as their parents, but there is also evidence that these children are at increased risk of developing a wide range of mental health disorders (Bijl, 2002; Lieb, 2002; Lizardi, 2004). For example, a large prospective longitudinal community study $(n=2427)$ conducted in Germany, demonstrated that major depression in parents increased the risk of their offspring having major depression, substance use disorder, bipolar disorder and anxiety disorder (Lieb, 2002). In a representative sample of the Dutch population $(n=78147)$, Biljl and colleagues $(2002)$ found that parental mental illness was strongly related to mental illness in their children independent of type of parental illness. When childhood adversities and demographic variables were controlled for, parental mental illness remained significant. A longitudinal study by Weissman (2006) in the USA found that children of parents with major depressive disorder had a five times greater risk of adolescent depression, a three times greater risk of anxiety disorder, and a five times greater risk of alcohol dependence when compared with children of parents without a psychiatric disorder. Increased risk of multiple disorders has also been reported among children of parents with schizophrenia in longitudinal studies (Hans, 2004; Keshavan, 2008; 
Niemi, 2004). This study demonstrates that children whose parents have a mental illness constitute an important high risk group.

Not only are children with a family history at elevated risk of developing a mental illness, they can also experience a home environment different from other children. A prospective cohort study involving children of the entire Danish population born after 1982 $(n=1,823,625)$ found that living arrangements of children whose parents had a serious mental illness (schizophrenia, bipolar affective disorder, or depression) differed from the general population (Ranning, 2016). Most children lived with a single mother or away from both parents, more relationships between parents had dissolved, and parents with schizophrenia had the most parenting difficulties.

Adolescents have reported in qualitative studies that when parents are hospitalised or acutely unwell, it is difficult for them to manage practically and emotionally (Fudge, 2004; Maybery, 2006). During a parent's hospitalization, the level of risk for children is high because there is no one to look after them particularly in single parent families (Maybery, 2009). The home environment might at times be chaotic and threatening (Maybery, 2009). Children report having problems accessing transport to visit their parent in hospital, limited finances, difficult separation from their siblings (e.g. whilst in foster care) and difficulty coping with the unfriendly nature of the psychiatric hospital environment. Adolescents also assumed domestic and caring responsibilities for their mentally ill parent and/or younger siblings, particularly in single parent families (Aldridge, 2003).

Findings from qualitative studies report adolescents can become socially isolated when they care for their mentally ill parent instead of spending time with friends or playing 
sports (Aldridge, 2003). Specific outcomes include higher dropout rates from school (Farahati, 2003) and an increased likelihood of being taken into state care (Leschied, 2005). This can result in high stress, attachment difficulties, exposure to abuse and neglect and identity problems (Ashman, 2002; Cicchetti, 1998; Goodman, 1999, Leinonen, 2003). A family history of mental illness is identified as a highly significant factor in ARMS (FusarPoli, 2012; 2013; 2016; Yung, 2004).

\section{Having a parent with mental illness and high school performance}

There is limited research relating to academic progress and having a parent with a mental illness. In the only study found that examined the link, Farahati and colleagues (2003), using survey methodology ( $\mathrm{n}=3389)$, reported an increased probability of high school dropout, particularly if there was maternal mental illness. One reason for this may be that a parent's mental illness limits their ability to be involved in their child's education. Parental involvement is known to facilitate positive youth development and improve academic functioning among adolescents (Epstein, 2006; Hill, 2004; Roeser, 2000; Seginer, 2006; Wang, 2012). In an American longitudinal study (Wang, 2014) (n = 1056; age 1517yrs), the researchers found that parental involvement improved academic and emotional functioning in adolescents and predicted academic achievement (Wang, 2014). Parents with mental illness may find contributions to their child's school life difficult to maintain, consequently impacting their child's school experience.

Family adversity can also negatively impact an adolescent’s achievements and participation in high school. In an American survey study examining the association between family adversity and academic outcomes ( $n=65,680$; age 6-17yrs), children 
experiencing family adversity were less likely to be engaged in school (Porche, 2016).

Chaotic home environments can result in school absenteeism while less parental monitoring can result in truancy and increased at risk behaviours (Chilcoat, 1996; Stattin, 2000).

Emotional unavailability and detached parenting results in practical neglect in terms of paying school fees, arriving on time to school, having clean uniforms, the provision of school lunches and being picked up at the correct time (Oysterman, 2000). Due to the difficulties parents with serious mental illness experience, adolescents may be less likely to engage in school, be required to take on domestic chores and responsibilities and encounter significant obstacles that impact effective participation in high school (Table 3).

\section{CLINICAL STAGING MODEL STAGE 1a - SLEEP DISTURBANCE, DETERIORATION IN FUNCTIONING, NON-SPECIFIC ANXIETY AND DEPRESSION}

\section{Sleep disturbance and ARMS}

Sleep is an adaptive function of humans during which the restoration of brain processes occur including strengthening of the immune system, growth, major metabolic processes, memory consolidation and brain plasticity (Durmer, 2005; Maquet, 1995; Stickgold, 2001). Sleep is vital to neural restoration and physiological maintenance across multiple systems (Chaput, 2016). Healthy sleep is linked to clearance of metabolic waste from the brain and enhancement of cognitive function (Konjarski, 2018). Sleep loss is linked to deficits in cognitive function, dysregulation of circadian processes such as cortisol secretion, and impaired emotional regulation (Short, 2015). There is increasing recognition that sleep disturbance is a contributory causal factor for many mental health problems (Harvey, 2009). Impaired sleep is established in research as a clinical risk factor for mood 
disorders, psychotic disorders and anxiety disorders (Briekzke 2012; Harvey, 2008; Ritter, 2012; Ruhrmann, 2010).

Sleep disturbance is defined in the research as detrimental changes to sleep function and include delays in falling asleep, difficulties with sleep maintenance, a reduction in total sleep time, multiple awakenings during sleep, nightmares and non-restorative sleep (Bensen, 2008; Carskadon, 2005; Lucchesi, 2005: Ohayon, 2004; Poulin, 2003; Zanini, 2013).

Adolescence may be a particular risk for the onset of sleep problems due to a combination of biological, social and environmental changes which occur during this period (Carskadon, 2005; Harvey, 2016). A shift in circadian rhythms following puberty interacts with social and behavioural changes in adolescence (such as reduced parental oversight and increased social media) to delay the sleep phase at night. The inability to delay the wake up time due to school results in a reduced sleep window and can precipitate sleep disturbance (Bradley, 2018). Thus sleep problems in adolescence are associated with mental health problems such as suicidal thoughts and self-harm behaviour (Gradisa, 2011; Johnson, 2006; Ohayon, 2004; Wong, 2011). Sleep disturbance represents an important treatment target for this age group, given the ongoing neurocognitive development and changes in sleep architecture that occur during this period. Sleep carries less stigma than mental health difficulties and is easy to talk about with young people.

International cross-sectional research, longitudinal naturalistic field studies, controlled clinical trials, and qualitative retrospective inquiries from Australia, Singapore, Greece and the USA have investigated sleep disturbance during the ARMS period (Andriopoulos, 2011; 
Gourzis, 2002; Iyer, 2008; Miller, 2003; Poe, 2017; Tan, 2001; Yung, 1996). The results indicate that sleep disturbances are one of the most common experiences. Longitudinal studies have found that sleep disturbance is a prominent reason for young people with ARMS to seek help (Ruhrmann, 2010). A retrospective American cross-sectional study also found sleep disturbance preceding death in a sample of adolescent suicide completers with emerging mental ill health ( $\mathrm{n}=140,13-19$ years) (Goldstein, 2008). Sleep disturbance could therefore be viewed as a warning sign of both deteriorating mental health and suicide risk for adolescents.

In a single blind randomised controlled trial conducted in the UK with students experiencing insomnia $(n=3755)$, the authors reported that students were less likely to meet criteria for ARMS after treatment for sleep disturbance (Bradley, 2018). Treating sleep disturbance in this population could potentially contribute to preventing progression of mental ill health (Bradley, 2018). There is no direct evidence that sleep problems correlate specifically with negative academic outcomes in ARMS samples because this has not been a research focus in youth mental health literature. The education literature will now be reviewed to ascertain the evidence about sleep disturbance and academic performance.

\section{Sleep disturbance and high school performance}

Over thirty years of worldwide education research has provided strong evidence that sleep is vital for optimal levels of executive function required for learning and has a significant influence on academic functioning during adolescence (Curcio, 2006; Dewald, 2010; Diekelmann, 2010; Drummond, 2000; Fallone, 2002; Taras, 2015). Cross-sectional and 
longitudinal studies have examined self-reported sleep quality, sleep duration and sleepiness in large samples and found a significant relationship with school performance (Chung, 2008; Drake, 2003; Fredriksen, 2004; Gibson, 2006; Joo, 2005; Lazaratou, 2005; Mak, 2012; Meijer, 2004; O’Brian, 2005; Pagel, 2010; Wolfson, 2003). The findings indicate that shortened sleep time, erratic sleep/wake patterns, late bed and rise times and poor sleep quality are negatively associated with academic performance for adolescents throughout high school characterised by low grades and school drop out (Curcio, 2006; Fallone, 2002; Wolfson, 1998). These results have been consistently found in multiple cross-sectional studies in Australia, Sweden, Finland, Norway, South America, Europe and Asia (Chung, 2008; Hysing, 2016; Kronholm, 2015; Lazaratou, 2005; Perez-Chada, 2007; Stea, 2014; Titova, 2015; Yang, 2005).

\section{Deterioration in functioning and ARMS}

Functioning is defined as the frequency, quality of, and satisfaction with one's social, academic or occupational daily activity (Cotter, 2014). Poor functioning is one of the most consistently reported symptoms in ARMS samples and a major reason why young people present for help to services (Addington, 2017; Amminger, 2006; Cannon, 2008; Cornblatt, 2007, 2015; Fusar-Poli, 2013, 2014; Lemos-Giraldez, 2009; Nelson, 2013; Niedman, 2006, 2014; Ruhrmann, 2010; Schlosser, 2012; Thompson, 2011; Valmaggia, 2013; Velthorst, 2009; 2010; Yung, 2004; 2006). Neurodevelopmental processes are believed to contribute to the deterioration of functioning associated with ARMS (Cotter, 2014). 
There is an increasing body of evidence demonstrating that individuals with ARMS experience deficits in multiple cognitive domains (Barbata, 2013; Brewer, 2006; Fusar-Poli, 2012; Niendam, 2014). A meta-analysis investigated the extent of cognitive dysfunction in an ARMS group and found that deficits of attention, verbal fluency, visual and verbal memory, working memory, executive functioning and social cognition were present (Fusar-Poli, 2012). In another meta-analysis, Fusar-Poli and colleagues (2015) found that the ARMS group had a quality of life similar to individuals with established psychotic disorders due to impaired functioning. A systematic review also found that negative and disorganised symptoms contributed to poor functioning in individuals with ARMS (Cotter, 2014). Motivation, organisation and cognition are important for learning and academic participation therefore high school success is likely to be more difficult for individuals experiencing ARMS.

A need for care exists to enable these individuals to compensate for the cognitive impact of ARMS and successfully manage their practical, social, occupational and academic requirements. There is no research evidence demonstrating that poor functioning correlates specifically with negative academic outcomes in ARMS samples because it has not been researched before.

\section{Depression, anxiety and ARMS}

Up to $20 \%$ of young people will experience a depressive episode or anxiety disorder by the age of 18 years (Kessler, 2007; Lewinsohn, 1993; Merry, 2011). Early onset depression and anxiety is associated with substance use, suicide risk and poor academic achievement (Birmaher, 1996; Johnansson, 2013; Kessing, 2004; Rao, 1995). 
Undifferentiated depression and anxiety are clinical risk factors for moderate to severe mood and anxiety disorders as well as transition to psychosis (Amminger, 2006; Bockting, 2006; Wigman, 2012; Yung, 2004).

Cross-sectional, longitudinal, randomised control trials and follow up studies worldwide report a high prevalence of depression and anxiety in ARMS samples (Addington, 2017; Bechdolf, 2010; Brandizzi, 2015; Falkenberg, 2015; Fulford, 2013; Fusar-Poli, 2014; Hui, 2013; Kelleher, 2012; Lim, 2015; McAusland, 2017; Sakokangas, 2012; Velthorst, 2010; Woods, 2009). For example, an Australian follow up study ( $\mathrm{n}=226)$ reported that $90 \%$ of their ARMS sample had depression and anxiety (Lim, 2015). Suicidal ideation has also been found to be high (59\%) (Hutton, 2011). In a multisite study examining the prevalence of anxiety specifically in an ARMS sample (765 ARMS individuals and 280 health controls), anxiety disorders were significantly more prevalent in those with ARMS when compared to healthy controls (McAusland, 2017). Fifty-one per cent had an anxiety disorder and social phobia was the most prevalent (McAusland, 2017). These results are consistent with other findings that social phobia is typically one of the most prevalent anxiety diagnoses in ARMS samples (Hui, 2013; McAusland, 2017; Meyer, 2014; Rietdijk, 2013; Rosen, 2006; Salokangas, 2012; Svirskis, 2005).

In a recent article, Davey and McGorry (2019) applied the clinical staging model to depression and identified that many young people will have subclinical depressive symptoms that don’t progress further. Others will have uncomplicated depression with comorbid anxiety (no suicidality), and others will have severe and complex depression that includes suicidal 
thoughts, poor psychosocial functioning and comorbid anxiety (Davey, 2019). The authors suggest that this is best managed in specialist youth mental health services, where expertise and support is available for them to recover.

There is no research demonstrating that depression and anxiety correlates specifically with negative academic outcomes in ARMS samples because this has not been a focus of previous research. The education literature will now be reviewed to ascertain the evidence about depression, anxiety and academic performance.

\section{Depression, anxiety and high school performance}

Adolescent depression and anxiety have been shown to negatively impact high school through poor grades and school drop out (Birmaher, 1996; Elmelid, 2015; Esch, 2014; Froyd, 2008; Garvik, 2014; Leach, 2012; Quiroga, 2013; Riglin, 2013; Van Amringen, 2003).

Longitudinal studies have found that depression and anxiety at the beginning of a school year predicts poor grades at the end of the year (Frojd, 2008; Weldman, 2015). The Australian National Survey of Mental Health and Wellbeing data $(\mathrm{n}=2055)$ found that depression and anxiety were significantly associated with disruption to the completion of Year 10 and high school dropout (Leach, 2012). A Canadian study $(n=493)$ found that depression in Year 7 predicted dropout within 6 years for over a third of high school students (Quiroga, 2013).

Several key symptoms of depression, such as impaired ability to concentrate, loss of interest, poor initiative, psychomotor retardation, low self-esteem, worthlessness and social withdrawal significantly reduce performance and initiative in learning (Esch, 2014; Frojd, 2008; Garvik, 2014; Quiroga, 2013). Depression results in students focusing on depressive 
thoughts and interpretations instead of the learning tasks (Frojd, 2008). Failures and negative feedback from teachers or peers further exacerbate feelings of hopelessness associated with depression (Birmaher, 1996; Garvik, 2014; Leach, 2012). Anxiety disorders, specifically social phobia and panic, are an important determinant for dropping out of school and academic underachievement (Davidson, 1993; Esch, 2014; Last, 1997; Van Ameringen, 2003; Weldman, 2015) (Table 4).

\section{CLINICAL STAGING MODEL STAGE 1b - ATTENUATED PSYCHIATRIC SYNDROMES; ULTRA HIGH RISK; SUBTHRESHOLD PSYCHOSIS AND BIPOLAR AFFECTIVE DISORDER}

\section{Subthreshold psychosis}

The ultra-high risk (UHR) for psychosis criteria created a paradigm for prediction research and subthreshold intervention and focuses on the identification of young people in the prodromal period of the disorder with the goal of delaying or preventing the onset of psychosis (FusarPoli, 2013; Yung, 1996, 2004). The Diagnostic and Statistical Manual of Mental Disorders, $5^{\text {th }}$ edition (DSM - 5) includes attenuated psychosis syndrome (APS) in Section III under “conditions for further study” (APA, 2013). Attenuated psychosis is a condition applied to young people showing their first (thus weak or attenuated) psychotic symptoms. Symptoms include hearing voices, disordered thinking, paranoia and social withdrawal that could, if left untreated, lead to schizophrenia or bipolar disorder.

Based on the evidence, the clinical staging model in psychosis comprises Stage 0 (family history of mental illness, history of childhood trauma), Stage 1a (sleep disturbance, deterioration in functioning, undifferentiated anxiety and depression) and Stage 1b (subthreshold or attenuated psychosis syndrome) (Addington, 2007, 2012; Cannon, 2008; 
Fusar-Poli, 2013, 2014; McGorry, 2018; Nelson, 2013; Ruhrmann, 2010;). Clinical predictors for progression to FEP (Stage 2) include persisting attenuated psychotic symptoms such as thought disorder, conceptual disorganisation, and unusual thought content such as paranoid thoughts, and poor functioning as well as negative symptoms (Addington, 2007, 2012, 2015; Amminger, 2006; Cannon, 2008 Cornblatt, 2015; Demjaha, 2012; Klosterkotter, 2001; Lemos-Giraldez, 2009; Schlosser, 2012; Thompson, 2011; Valmaggia, 2013; Velthorst, 2009; Yung, 1996, 2004; Ziermans, 2014).

In an English survey study with 130 secondary school teachers, Collins and colleagues (2008) investigated high school teachers' knowledge of FEP and their views about their role in early detection. The authors found that almost a third of the sample had experienced a student with possible symptoms of psychosis but most teachers were unsure about their role and who had the responsibility to help, how to help and where to refer them. An Italian study with high school teachers $(\mathrm{n}=268)$ found similar results (Masillo, 2012). Further, in a Norwegian cross sectional study $(n=441)$, access to a school youth mental health outreach team for early detection and treatment of psychosis demonstrated that this increased confidence for teachers in recognising and supporting students (Langeveld, 2011). The evidence shows that in order to recognise early symptoms of psychosis, teachers require youth mental health support structures and knowledge of the available resources. The education literature will now be discussed.

\section{Subthreshold psychosis and high school performance}


There is no research in education about the impact of psychosis and school performance. This may be because students have already dropped out or school staff mistake symptoms of emerging psychosis for depression and anxiety or substance use. However, in Waghorn's Australian analysis of the data from the second national survey with individuals experiencing psychosis $(\mathrm{n}=1825)(2012), 68 \%$ of the sample had not finished high school (2012). Having no high school qualification was more common in those with schizophrenia (36.6\%) or schizoaffective disorder (36.8\%) compared with bipolar affective disorder (27.6\%). Differences in educational attainment were statistically significant $(p=0.0004)$. These results were a lot worse than the previous national psychosis survey in 1999 when $47.8 \%$ of the sample had not completed high school. The evidence indicates that subthreshold psychosis is not identified early in high school and consequently contributes considerably to the global economic burden of schizophrenia and psychotic disorders.

\section{Subthreshold bipolar affective disorder (BPAD)}

Bipolar affective disorder (BPAD) is one of most burdensome conditions in young people aged under 25 years with a peak age at onset of between 15 and 25 years (Gore, 2011; Kessler, 2007). Research suggests that young people with BPAD experience functional impairments early in the illness with high rates of NEET present (Alonso, 2011; Cross, 2017; Dean, 2004; Gilbert, 2013; Goldstein, 2009; Grande, 2013; Hirschfeld, 2003; Jansen, 2012; Judd, 2008; Kaur-Sant’Anna, 2009; Morriss, 2013; Simon, 2007, 2008; Tickell, 2019). The social and economic consequences of BPAD have reinforced the need to promote effective interventions in the earliest phases of illness (Balazs, 2013; McGorry, 2006; Scott, 2012; Scott, 2013). 
International evidence indicates that individuals at high risk of developing BPAD (Stage 2) often report depressive, hypomanic or psychotic-like presentations in the months or even years prior to the first episode that meets full diagnostic criteria for the illness (Berk, 2014; Kapczinski, 2014; Scott, 2013). Retrospective studies demonstrate that symptom onset occurs during adolescence with several depressive episodes preceding the first hypomanic episode (Beesdo, 2009; Frankland, 2018; Kupfer, 2002). Studies have found that sleep disturbance, anxiety and depression, mood lability, disruptive behaviour, and irritability can also precede the onset of subthreshold hypomanic symptoms (Axelson, 2015; Egeland, 2000; Hafeman, 2016; Hauser, 2013; Mesman, 2017).

In terms of clinical staging, the identified risk markers of BPAD are having a family history of mental illness, a history of trauma (Stage 0); sleep disturbance, poor psychosocial functioning, undifferentiated anxiety and depression, (Stage 1a); followed by moderate depressive symptoms, mood lability and irritability leading to a subthreshold hypomanic episode (Stage 1b), (Berk, 2014; Duffy, 2010, 2014; Hartmann, 2018; Kapczinski, 2014; Scott, 2013).

\section{Subthreshold BPAD and high school performance}

There is no research in the education literature about the impact of BPAD on school performance. This may be due to teachers' lack of awareness of subthreshold hypomanic symptoms, or mistaking mood lability and irritability as behavioural, or related specifically to substance use. There is no clear and consistent data reporting the high school success rates of young people experiencing BPAD in the mental health literature. There is evidence that 
neuropsychological changes such as difficulties in mental flexibility (Hermans, 2011), attention (Thompson, 2005), memory (Thompson, 2005) and executive functioning (Sweeney, 2000), accompany the first episode BPAD, all of which would negatively impact school performance (Lin, 2013).

Some international studies report that they young people with BPAD more likely to complete high school than those experiencing psychosis (MacCade, 2010; Vreeker, 2016). Others report significantly poor high school performance (Dean 2004; Grande, 2013; Scott, 2014). International mental health research demonstrates that following a first episode of BPAD (Stage 2), functional recovery is difficult to obtain and is only achieved by approximately a third of individuals (Dion, 1988; Tohen, 2000; Scott, 2014). In a cross sectional study ( $n=1241)$, 36\% of the sample were receiving government financial support due to vocational inactivity and serious impairments in functioning (Scott, 2014). It is suggested that school dropout may frequently occur but is not consistently recorded in research. Waghorn (2012) reported in the second national survey with individuals experiencing psychosis $(n=1825)$ that of the $68 \%$ that had not finished school, $27.6 \%$ had BPAD. It is clear from the research that clinical improvement in BPAD is not necessarily associated with functional recovery. Please see Table 5 for the key findings related to Clinical Stage 1b.

\section{DISCUSSION}

Untreated mental ill health is the major cause of high school dropout and risk factor for NEET. There is little acknowledgement in the youth mental health literature about 
emerging mental ill health, the Clinical Staging Model and the academic success of young people. There is however evidence in the education literature about the student characteristics that negatively impact high school participation and achievement, and this study demonstrated that these correspond to the characteristics of Clinical Staging Model, specifically Stages 0 and $1 \mathrm{a}$.

It is argued that the school environment offers unparalleled access to young people in a familiar environment (Masia-Warneret, 2006). School based mental health services integrated into the school life could alleviate many barriers to accessing treatment for young people and promote early identification and intervention (Barrett, 2006). The education evidence shows that the risk markers for emerging mental ill health can have a negative impact on a student's ability to engage, participate and succeed both academically and socially in high school. Teachers are not supposed to be mental health clinicians, but it is evident from the literature that they can already identify the characteristics consistent with Stage 0 and 1a of the Clinical Staging Model. Stage $1 \mathrm{~b}$ subthreshold states are however more difficult for teachers to recognise and consequently are not included in the education literature. It may be easier and less stigmatising for school personnel to ascertain if a student is experiencing poor sleep and having trouble with their functioning than to ask about attenuated psychotic symptoms. This evidence should be capitalised upon. Once a student is identified by a teacher as experiencing risk markers, then clear referral protocols need to be embedded into school life.

Headspace is the Australian Government's major investment in youth mental health (Rickwood, 2013). Headspace centres are youth- friendly and provide evidence based 
interventions and support to young people experiencing mental ill health (Rickwood, 2018). Young people accessing headspace report high levels of satisfaction with the service provided (Rickwood, 2015). Research has demonstrated that headspace support can improve psychological distress and/or social and occupational functioning (Rickwood, 2015). It is however largely office or centre-based operating in the hours when students should be in school. It needs to expand into the community with outreach and mobile care to effectively service the need. Rural areas are particularly in need, where access to services is limited by long wait lists for help, the need to travel to access help but limited public transport exists (Bowman, 2017). Headspace school mobile outreach teams consisting of youth mental health clinicians, and psychiatrists should provide onsite school support, early intervention and treatment to prevent illness progression, promote recovery and achievement of academic goals. This could genuinely reduce the risk of young people prematurely dropping out due to their mental ill health and lead to better educational and social outcomes.

\section{References}

ACOEM (2009). Guidance Statement Healthy workforce/healthy economy: the role of health, productivity, and disability management in addressing the nation's health care crisis: why an emphasis on the health of the workforce is vital to the health of the economy. $J$ Occup Environ Med., 51: 114-119.

Addington, J., Cadenhead, K., Cannon, T., Cornblatt, B., McGlashan, T., Perkins, D., Seidman, L., Tsuang, M., Walker, E., Woods, S., Heinssen, R. (2007). North American Prodrome Longitudinal Study: A Collaborative Multisite Approach to Prodromal Schizophrenia Research, Schizophrenia Bulletin, 33 (3): 665-672.

Addington, J., Cadenhead, K. S., Cornblatt, B. A., Mathalon, D. H., McGlashan, T. H., Perkins, D. O., ... Cannon, T. D. (2012). North American Prodrome Longitudinal Study (NAPLS 2): overview and recruitment. Schizophrenia research, 142 (1-3), 77-82. 
Addington, J., Cornblatt, B., Cadenhead, K., Cannon, T., et al. (2011). At clinical high risk for psychosis: outcome for nonconverters. Am. J. Psychiatry, 168 (8): 800-805.

Addington J., Liu L., Buchy L., Cadenhead K.S., Cannon T.D., Cornblatt B.A., Perkins D.O., Seidman L.J., Tsuang M.T., Walker E.F., Woods S.W., Bearden C.E., Mathalon D.H., McGlashan T.H. (2015). North American Prodrome Longitudinal Study (NAPLS 2): The Prodromal Symptoms. J Nerv Ment Dis., 23 (5): 328-335.

Addington, J., Liu, L., Perkins, D. O., Carrion, R. E., Keefe, R. S. E., \& Woods, S. W. (2017). The Role of Cognition and Social Functioning as Predictors in the Transition to Psychosis for Youth with Attenuated Psychotic Symptoms. Schizophrenia Bulletin, 43(1): 57-63.

Addington, J., Piskulic, D., Liu, L., Lockwood, J., et al. (2017). Comorbid diagnoses for youth at clinical high risk of psychosis. Schizophrenia Research, 190: 90-95.

Addington, J., Stowkowy, J., Cadenhead, K., Cornblatt, B., McGlashan, T., Perkins, D., ... Cannon, T. (2013). Early traumatic experiences in those at clinical high risk for psychosis. Early Intervention in Psychiatry, 7 (3): 300-305.

Aldridge, J., Becker, S. (2003). Children Caring for Parents with Mental Illness: Perspectives of Young Carers, Parents and Professionals. Policy Press. 186134399X, 9781861343994

Al Mamun, A., Alati, R., O’Callaghan, M., Hayatbakhsh, M., O’Callaghan, F., Najman, J., et al. (2007). Does childhood sexual abuse have an effect on young adults' nicotine disorder (dependence or withdrawal)? Evidence from a birth cohort study. Addiction, 102 (4): 647-54.

Alonso, J., Petukhova, M., Vilagut, G., Chatterji, S., Heeringa, S., Üstün, T. B., ... Kessler, R. C. (2011). Days out of role due to common physical and mental conditions: results from the WHO World Mental Health surveys. Molecular Psychiatry, 16(12), 1234-1246.

American Psychiatric Association (APA). (2013). Diagnostic and statistical manual of mental disorders ( $5^{\text {th }}$ edition). Washington DC.

Amminger, G., Leicester, S., Yung, A., Phillips, L., Berger, G., Francey, S., Yuen, H.P., McGorry, P. (2006). Early-onset of symptoms predicts conversion to non-affective psychosis in ultra-high risk individuals. Schizophrenia Research, 84 (1): 67-76.

Andlin-Sobocki, P., Jonsson, B., Wittchen, H., Olesen, J. (2005). Cost of disorders of the brain in Europe. Eur J Neurol., 12 (Suppl 1): 1-27.

Andriopoulos, J., Ellul, M., Skokou, S., Beratis. (2011). Suicidality in the “prodromal” phase of schizophrenia. Compr Psychiatry, 52: 479-485. 
Arnett J. (2010). Adolescence and emerging adulthood: A cultural approach. (4th ed.) New York: Prentice Hall.

Ashman, S.B., Dawson, G., Panagiotides, H., Yamada, E., \& Wilkinson, C.W. (2002). Stress hormone levels of children of depressed mothers. Development and Psychopathology, 14 (2): 333-349.

Australian Bureau of Statistics. (2008). National survey of mental health and wellbeing: summary of results, 2007. Cat no 4326.0 Canberra: Australian Bureau of Statistics.

Australian Institute of Health and Welfare. (2011). Young Australians: their health and wellbeing. Canberra: Australian Institute of Health and Welfare.

Axelson, D., Goldstein, B., Goldstein, T., Monk, K., Yu, H., Hickey, M. B., et al. (2015). Diagnostic precursors to bipolar disorder in offspring of parents with bipolar disorder: a longitudinal study. The American Journal of Psychiatry, 172 (7): 638-646.

Balazs, J., Miklosi, M., Kereszteny, A., Hoven, C., Carli, V., Wasserman, C., et al. (2013). Adolescent subthreshold-depression and anxiety: psychopathology, functional impairment and increased suicide risk. J Child Psychol Psychiatry, 54: 670-7.

Barbato, M., Liu, L., Penn, D., Keefe, R., et al. (2013). Social cognition as a mediator between neurocognition and functional outcome in individuals at clinical high risk for psychosis. Schizophr. Res, 150 (2-3): 542-546.

Barrett, P., Pahl, K. (2006). School-based interventions: Examining a universal approach to anxiety management. Journal of Psychologists and Counsellors in Schools, 16: 55-75.

Bechdolf, A., Ratheesh, A., Cotton, S. M., Nelson, B., Chanen, A. M., Betts, J., et al. (2014). The predictive validity of bipolar at-risk (prodromal) criteria in help-seeking adolescents and young adults: a prospective study. Bipolar Disorders, 16(5): 493-504.

Bechdolf, A., Thompson, A., Nelson, B., Cotton, S., Simmons, M., Amminger, G., ... Sidis, A. (2010). Experience of trauma and conversion to psychosis in an ultra-high-risk (prodromal) group. Acta Psychiatrica Scandinavia, 121 (5): 377-384.

Beesdo, K., Höfler, M., Leibenluft, E., Lieb, R., Bauer, M., Pfennig, A. (2009). Mood episodes and mood disorders: patterns of incidence and conversion in the first three decades of life. Bipolar Disorder, 11 (6): 637-649.

Bendall, S., Jackson, H., Hulbert, C., McGorry, P. (2008). Childhood Trauma and Psychotic Disorders: a Systematic, Critical Review of the Evidence. Schizophr Bull. 34 (3): 568-579. 
Benjet C, Hernández-Montoya D, Borges G, Mendez E, Medina-Mora ME, Aguilar- Gaxiola S. (2012). Youth who neither study nor work: mental health, education and employment. Salud Publica Mex; 54: 410-7.

Benson, K. L. (2008). Sleep in Schizophrenia. Sleep Medicine Clinics, 3: 251-260.

Berk, M., Berk, L., Dodd, S., Cotton, S., Macneil, C., Daglas, R., et al. (2014). Stage managing bipolar disorder. Bipolar Disorders, 16 (5): 471-477.

Bijl, R.V., Cuijpers, P., \& Smit, F. (2002). Psychiatric disorders in adult children of parents with a history of psychopathology. Social Psychiatry and Psychiatric Epidemiology, 37(1): 7-12.

Birmaher, B., Axelson, D., Monk, K., Kalas, C., Goldstein, B., Hickey, M.B., et al. (2009). Lifetime psychiatric disorders in school-aged offspring of parents with bipolar disorder: the Pittsburgh Bipolar Offspring Study. Archives of General Psychiatry, 66(3), 287-296.

Birmaher, B., Ryan, N., Williamson, D., et al. (1996). Childhood and adolescent depression: A review of the past 10 years. Part I. Journal of the American Academy of Child and Adolescent Psychiatry, 35: 1427-1439.

Black, D.W., Gaffney, G.R., Schlosser, S., \& Gabel, J. (2003). Children of parents with obsessive-compulsive disorder - 2-year follow-up study. Acta Psychiatrica Scandinavica, 107 (4): 305-313.

Bloom, D., Cafiero, E., Jane-Llopis, E., Abrahams-Gessel, S., Bloom, L., Fathima, S., Feigl, A., Gaziano, T., Mowafi, M., Pandya, M., Prettner, K., Rosenberg, I., Sligman, B., Stein, A., Weinstein, C. (2011). The global economic burden of noncommunicable diseases. Geneva: World Economic Forum.

Bockting, C., Spinhoven, P., Koeter, M., Wouters, L., Schene, A. (2006). Prediction of recurrence in recurrent depression and the influence of consecutive episodes on vulnerability for depression: a 2 years prospective study. Journal Clinical Psychiatry, 67 747-755.

Bowman, S., McKinstry, C, McGorry, P. (2017). Youth mental ill health and secondary school completion in Australia - time to act. Early Intervention in Psychiatry, 11 (4): 277289.

Bowman, S., Alvarez-Jimenez, M., Wade, D., Howie, L., McGorry, P. (2017). The positive and negative experiences of caregiving for siblings of young people with first episode psychosis. Frontiers in Psychology, 23 (8): 730.

Bradley J, Freeman D, Chadwick E, et al. (2018). Treating Sleep Problems in Young People at Ultra-High Risk of Psychosis: A Feasibility Case Series. Behav Cogn Psychother., 46 (3): 276-291. 
Brandizzi, M., Valmaggia, L., Byrne, M., Jones, C., et al. (2015). Predictors of functional outcome in individuals ay high clinical risk for psychosis at six years follow-up. Journal of Psychiatric Research, 65: 115-123.

Brewer, W. J., Wood, S. J., Phillips, L. J., Francey, S. M., Pantelis, C., Yung, A. R., ... McGorry, P. D. (2006). Generalized and Specific Cognitive Performance in Clinical HighRisk Cohorts: A Review Highlighting Potential Vulnerability Markers for Psychosis. Schizophrenia Bulletin, 32 (3): 538-555.

Brietzke, E., Mansur, R., Soczynska, J., Kapczinski, F., Bressan, R., McIntyre, R. (2012). Towards a multifactorial approach for prediction of bipolar disorder in at risk populations. Journal of Affective Disorders, 140 (1): 82-91.

Bronisch, T. \& Lieb, R. (2008). Maternal suicidality and suicide risk in offspring. Psychiatric Clinics of North America, 31 (2): 213-221.

Calear, A., Christensen, H. (2010). Systematic review of school-based prevention and early intervention programs for depression. Journal of Adolescence, 33: 429-438.

Campbell, M., Morrison, A. (2007). The relationship between bullying, psychotic-like experiences and appraisals in 14-16-year olds. Behav Res Ther, 45 (7): 1579-91.

Cannon, T. (2005). Clinical and genetic high-risk strategies in understanding vulnerability to psychosis. Schizophrenia Research, 79 (1): 35-44.

Cannon, T., Cadenhead, K., Cornblatt, B. (2008). Prediction of psychosis in youth at high clinical risk: a multisite longitudinal study in North America. Arch Gen Psychiatry, 65: 2837.

Carskadon, M., Dement, W. (2005). Normal Human Sleep, Principles and Practice of Sleep Medicine ( $4^{\text {th }}$ Edition), edited by Kryger, M., Roth, T., Dement, W. Elsevier Inc. 3-13.

Carter, J., Parnas, J., Cannon, T., Schulsinger, F., Mednick, S. (1999). MMPI variables predictive of schizophrenia in the Copenhagen High Risk Project: a 25 year follow up. Acta Psychiatr Scandinavia, 99: 432-440.

Chapman, D., Whitfield, C., Felitti, V., Dube, S., Edwards, V., Anda, R. (2004). Adverse childhood experiences and the risk of depressive disorders in adulthood. Journal of Affective Disorders, 82 (20): 217-225, 2004.

Chaput, J., Gray, C., Poitras, V., Carson, V., Gruber, R., Olds, T., Weiss, S., Connor Gorber, S., Kho, M., Sampson, M., et al. (2016). Systematic review of the relationships between sleep duration and health indicators in school-aged children and youth. Applied psychsiology, Nutrition and Metabolism, 41: S266-S282. 
Chilcoat, H., Breslau, N., Anthony, J. (1996). Barriers to parental monitoring: social disadvantage, marital status and maternal psychiatric disorder. Journal of the American Academy of Child \& Adolescent Psychiatry, 35 (12): 1673-1682.

Chung, K. (2008). Sleep-wake patterns and sleep disturbance among Hong Kong Chinese adolescents. Sleep, 31: 85-194.

Cicchetti, D., Rogosch, F.A., \& Toth, S.L. (1998). Maternal depressive disorder and contextual risk: Contributions to the development of attachment insecurity and behavior problems in toddlerhood. Development and Psychopathology, 10 (2), 283-300.

Collins, A., Holmshaw, J. (2008). Early detection: a survey of secondary school teachers' knowledge and psychosis. Early Intervention in Psychiatry, 2: 90-97.

Coolidge, F.L., Thede, L.L., \& Jang, K.L. (2001). Heritability of personality disorders in childhood: A preliminary investigation. Journal of Personality Disorders, 15 (1), 33-40.

Cornblatt, B., Auther, A., Niendam, T., Smith, C., et al. (2007). Preliminary findings for two new measures of social and role functioning in the prodromal phase of schizophrenia.

Schizophr. Bull., 33 (3): 688-702.

Cornblatt, B. A., Carrión, R. E., Auther, A., McLaughlin, D., Olsen, R. H., John, M., \& Correll, C. U. (2015). Psychosis Prevention: A Modified Clinical High Risk Perspective From the Recognition and Prevention (RAP) Program. The American journal of psychiatry,

Cotter, J., Drake, R., Bucci., Yung, A. (2014). What drives poor functioning in the at-risk mental state? A systematic review. Schizophrenia Research, 159: 2-3).

Cotter, J., Drake, R., Yung, A. (2016). Adulthood revictimization: looking beyond childhood trauma. Acta Psychiatrica Scandinavica, 134 (4): 368-368.

Cotter, J., Kaess, M., \& Yung, A. R. (2015). Childhood trauma and functional disability in psychosis, bipolar disorder and borderline personality disorder: A review of the literature. Irish Journal of Psychological Medicine, 32(Spec Iss1), 21-30.

Cross S, Hermens D, Scott E, Ottario A, McGorry P. (2014). A clinical staging model for Early Intervention Youth Mental Health services. Psychiatr Serv, 65 (7): 939-943.

Cross S., Hickie I. (2017). Transdiagnostic stepped care in mental health. Public Health Res Pract., 27 (2): e2721712.

Curcio, G., Ferrara, M., De Gennaro, L. (2006). Sleep loss, learning capacity and academic performance. Sleep Med Rev, 10; 323-337.

Daignault, I., \& Hebert, M. (2009). Profiles of school adaptation: social, behavioral and academic functioning in sexually abused girls. Child Abuse Negl., 33 (2): 102-115. 
Davey, C., McGorry, P. (2019). Early intervention for depression in young people: a blind spot in mental health care. The Lancet, 6: 267 - 272.

Davidson, J., Hughes, D., George, K., Blazer, D. (1993). The epidemiology of social phobia: findings from the Duke Epidemiological Catchment Area Study. Psychol Med, 23: 709-718.

Davis, K., Collins, S., Doty, M., Ho, A., Holmgren, A. (2005). Health and productivity among US workers. Issue Brief (Commonw Fund), 856:1-10.

Dean, B., Gerner, D., Gerner, R. (2004). A systematic review evaluating health-related quality of life, work impairment, and healthcare costs and utilization in bipolar disorder. Current Medical Research and Opinion, 20 (2): 139-154.

De Bellis, M. D., \& Zisk, A. (2014). The biological effects of childhood trauma. Child and Adolescent Psychiatric Clinics of North America, 23: 185-222.

Delaney-Black, V., Covington, C., Ondersma, S. J., Nordstrom- Klee, B., Templin, T., Ager, J., et al. (2002). Violence exposure, trauma, and IQ and/or reading deficits among urban children. Archives of Pediatrics and Adolescent Medicine, 156: 280-285.

DelBello, M.P. \& Geller, B. (2001). Review of studies of child and adolescent offspring of bipolar parents. Bipolar Disorders, 3(6): 325-334.

Demjaha, A., Valmaggia, L., Stahl, D., Byrne, M., Mcguire. P. (2012).

Disorganization/cognitive and negative symptom dimensions in the at-risk mental state predict subsequent transition to psychosis. Schizophr Bull, 38: 351-359.

DePrince, A. P., Weinzierl, K. M., \& Combs, M. D. (2009). Executive function performance and traumatic event exposure in a community sample of children. Child Abuse and Neglect, 33: 353-361.

Devylder, J., Ben-David, S., Schobel, S., Kimhy, D., Malaspina, D., Corcoran, C. (2013). Temporal association of stress sensitivity and symptoms in individuals at clinical high risk for psychosis. Psychol Med, 43 (2): 259-68.

Dewald, J., Meijer, A., Oort, F., Kerkhof, G., Bogels, S. (2010). The influence of sleep quality, sleep duration and sleepiness on school performance in children and adolescents: A meta-analytic review. Sleep Medicine Reviews, 14 (3): 179-189.

de Wit, S., Schothorst, P., Oranje, B., Ziermans, T., et al. (2014). Adolescents at ultra-high risk for psychosis: long-term outcome of individuals who recover from their at-risk state. Eur. Neuropsychopharmacol., 24 (6): 865-873. 
Diekelmann, S., Born, J. (2010). The memory function of sleep. Nat Res Neurosci, 11 (2): 114-126.

Dion, G., Tohen, M., Anthony, A., Waternaux, C. (1988). Symptom and functioning of patients with bipolar disorder six months after hospitalisation. Hospital and Community Psychiatry, 39 (6): 652-657.

Drake, C., Nickel, E., Burduvali, T., Roth, C., Jefferson, B. (2003). The pediatric daytime sleepiness scale (PDSS): sleep habits and school outcomes in middle-school children. Sleep, 26: 455-458.

Drummond, S. (2000). Altered brain response to verbal learning following sleep deprivation. Nature, 403: 655-657.

Dube, S., Anda, R., Whitfield, C., Brown, D., Felitti, V., Dong, M., et al. (2005). Long-term consequences of childhood sexual abuse by gender of victim. Am J Prev Med, 28 (5): 430-8.

Duffy, A., Alda, M., Hajek, T., Sherry, S. B., \& Grof, P. (2010). Early stages in the development of bipolar disorder. Journal of Affective Disorders, 121 (1-2): 127-135.

Duffy, A., Horrocks, J., Doucette, S., Keown-Stoneman, C., McCloskey, S., \& Grof, P. (2014). The developmental trajectory of bipolar disorder. The British Journal of Psychiatry, 204 (2): 122-128.

Duplechain, R., Reigner, R., \& Packard, A. (2008). Striking differences: The impact of moderate and high trauma on reading achievement. Reading Psychology, 29: 117-136.

Durmer, J., Dinges, D. (2005). Neurocognitive consequences of sleep deprivation Semin. Neurol., 25 (1): 117-129.

Egeland, J. A., Hostetter, A. M., Pauls, D. L., \& Sussex, J. N. (2000). Prodromal symptoms before onset of manic-depressive disorder suggested by first hospital admission histories. Journal of the American Academy of Child and Adolescent Psychiatry, 39 (10): 1245-1252.

Elbert, T., Schauer, M., Schauer, E., Huschka, B., Hirth, M.,\& Neuner, F. (2009). Traumarelated impairment in children- A survey in Sri Lankan provinces affected by armed conflict. Child Abuse and Neglect, 33: 238-246.

Elmelid, A., Stickley, A., Lindblad, F., Schwab-Stone, M., Henrich, C. C., Ruchkin, V. (2015). Depressive symptoms, anxiety and academic motivation in youth: do schools and families make a difference? J. Adolesc, 45:174-182.

Epstein, J., Sanders, M. (2006). Prospects for change: preparing educators for school, family and community partnerships. Peabody Journal of Education, 81 (2): 81-120. 
Esch, P., Bocquet, V., Pull, C., et al. (2014). The downward spiral of mental disorders and educational attainment: a systematic review on early school leaving. BMC Psychiatry, 14: 237-350.

Eurofound. NEETs - Young People Not in Employment, Education or Training: Characteristics, Costs and Policy Responses in Europe. (2012). Luxembourg: Publications Office of the European Union.

Falkenberg, I., Valmaggia, L., Byrnes, M., Frascarelli, M., et al. (2015). Why are helpseeking subjects at ultra-high risk for psychosis help-seeking? Psychiatry Res, 228 (3): 808815.

Fallone, G., Owens, J., Deane, J. (2002). Sleepiness in children and adolescents: clinical implications. Sleep Med Rev, 6: 287-306.

Falukozi, E., \& Addington, J. (2012). Impact of Trauma on Attenuated Psychotic Symptoms. Psychosis, 4 (3): 203-212.

Fantuzzo, J. W., Perlman, S. M., \& Dobbins, E. K. (2011). Types and timing of child maltreatment and early school success: A population-based investigation. Children and Youth Services Review, 33: 1404-1411.

Farahati, F., Marcotte, D., Wilcox-Gok, V. (2003). The effects of parents' psychiatric disorders on children's high school dropout. Economies of Education Review, 22: 163-178.

Felitti, V., Anda, R., Nordenberg, D., Williamson, D., Spitz, A., Edwards, V., et al. (1998). Relationship of childhood abuse and household dysfunction to many of the leading causes of death in adults. The Adverse Childhood Experiences (ACE) Study. Am J Prev Med, 14 (4): 245-58.

Fernando, S., Beblo, T., Schlosser, N., Terfehr, K., et al. (2014) The Impact of Self-Reported Childhood Trauma on Emotion Regulation in Borderline Personality Disorder and Major Depression. Journal of Trauma \& Dissociation, 15 (4): 384-401.

Frankland, A., Roberts, G., Holmes-Preston, E., Perich, T., Levy, F., Lenroot, R., . . . Mitchell, P. (2018). Clinical predictors of conversion to bipolar disorder in a prospective longitudinal familial high-risk sample: Focus on depressive features. Psychological Medicine, 48 (10): 1713-1721.

Franzen, E., Kassman, A. (2005). Longer-term labour market consequences of economic inactivity during young adulthood: a Swedish national cohort study. Journal of Youth Studies, 8 (4), 403-424.

Fredriksen, K., Rhodes, J., Reddy, R., Way, N. (2004). Sleepless in Chicago: tracking the effects of adolescent sleep loss during the middle school years. Child Dev, 75; 84-95. 
Frojd, S., Nissiene, E., Pelkonen, M., Marttunen, M., et al. (2008). Depression and school performance in middle adolescent boys and girls. Journal of Adolescence, 31 (4): 485-498.

Fudge \& Mason, 2004; Fudge, E. \& Mason, P. (2004). Consulting with young people about service guidelines relating to parental mental illness. Australian e-Journal for the Advancement of Mental Health 3, http://amh.econtentmanagement.com/archives/vol/3/issue/2/article e/3379/consulting-with-young-peopleabout-service.

Fulford, D., Niendam, T., Floyd, E., Carter, C., et al., (2013). Symptom dimensions and functional impairment in early psychosis: more to the story than just negative symptoms Schizophr. Res., 147 (1): 125-131.

Fusar-Poli, P., Bonoldi, I., Yung, A., Borgwardt, S., Kempton, M., Valmaggia, L., Barale, F., Caverzasi, E., McGuire P. (2012). Predicting psychosis: meta-analysis of transition outcomes in individuals at high clinical risk. Arch. Gen. Psychiatry, 69 (3): 220-229.

Fusar-Poli, P., Borgwardt, S., Bechdolf, A., et al. (2013). The Psychosis High-Risk State: A Comprehensive State-of-the-Art Review. JAMA psychiatry, 70 (1): 107-120.

Fusar-Poli, P., Bryne, M., Badger, S., Valmaggia, L., McGuire., P. (2013). Outreach and support in South London (OASIS), 2001-2011: ten years of early diagnosis and treatment for young individuals at high risk for psychosis. European Psychiatry, 28 (5): 315-316.

Fusar-Poli, P., Cappucciati, M., Borgwardt, S., Woods et al. (2016). Heterogeneity of psychosis risk within individuals at clinical high risk: a meta-analytical stratification. JAMA Psychiatry, 73 (2): 113-120.

Fusar-Poli, P., Nelson, B., Valmaggia, L., Yung, A., McGuire, P. (2014). Comorbid depressive and anxiety disorders in 509 individuals with an at-risk mental state: impact on psychopathology and transition to psychosis. Schizophr. Bull, 40 (1): 120-131.

Fusar-Poli, P., Rocchetti, M., Sardella, A., Avila, A., et al. (2015). Disorder, not just state of risk: meta-analysis of functioning and quality of life in people at high risk of psychosis. British Journal of Psychiatry, 207 (3): 198-206.

Garvik, M., Idsoe, T., Bru, E. (2014). Effectiveness study of a CBT-based adolescent coping with depression course. Emotional and Behavioural Difficulties, 19 (2): 195-209.

Gerrity, E., Folcarelli, C. (2008). Child Traumatic Stress: What Every Policymaker Should Know. Los Angeles, CA; Durham, NC: National Center for Child Traumatic Stress.

Gibb, B., Chelminski, I., Zimmerman, M. (2007). Childhood emotional, physical, and sexual abuse, and diagnoses of depressive and anxiety disorders in adult psychiatric outpatients. Depression and Anxiety, 24 (4): 256-263, 2007. 
Gibson, E., Powles, A., Thabane, L., O'Brien, S., et al. (2006). Sleepiness is serious in adolescence: two surveys of 3235 Canadian students. BMC Public Health, 6: 116.

Gilbert, E., Marwaha, S. (2013). Predictors of employment in bipolar disorder: A systematic review. Journal of Affective Disorders, 145 (2). 156-164.

Goldstein, T., Birmaher, B., Axelson, D., Goldstien, ZB., Gill, M., Esposito-Smythers, et a. (2009). Psychosocial functioning among bipolar youth. Journal of Affective disorders, 114: 174-183.

Goldstein, T. R., Bridge, J. A., Brent, D. A. (2008). Sleep Disturbance Preceding Completed Suicide in Adolescents. Journal of Consulting and Clinical Psychology, 76 (1): 84.

Goodman, S.H. \& Gotlib, I.H. (1999). Risk for psychopathology in the children of depressed mothers: A developmental model for understanding mechanisms of transmission.

Psychological Review, 106 (3): 458-490.

Gore, F., Bloem, P., Patton, G., Ferguson, J., Joseph, V., Coffey, C, et al. (2011). Global burden of disease in young people aged 10-24 years: a systematic analysis. Lancet, 377: 2093-102.

Goulding S, Chien V, Compton M. (2010). Prevalence and correlates of school drop-out prior to initial treatment of nonaffective psychosis: further evidence suggesting a need for supported education. Schizophr Res, 116 (2-3): 228-33.

Gourzis, P., Katrivanou, A., Beratis, S. (2002). Symptomatology of the initial prodromal phase in schizophrenia. Schizophr Bull, 28: 415-429.

Gradisar M., Gardner G. and Dohnt H. (2011). Recent worldwide sleep patterns and problems during adolescence: a review and meta-analysis of age, region, and sleep. Sleep Medicine, 12: 110-118.

Grande, I., Goikolea, J., de Dios, C., González-Pinto, A., Montes, J., Saiz-Ruiz, J et al. (2013). Occupational disability in bipolar disorder: analysis of predictors of being on severe disablement benefit (PREBIS study data). Acta Psychiatr Scand., 127: 403-411.

Grierson, A., Scott, J., Clozier, N., Hickie, I., Amminger, P., Killackey, E., et al. (2018). Can youth at high risk of illness progression be identified by measures of rumination a sleep-wake cycle. Early Intervention in Psychiatry, doi: 10.1111/eip.12757

Hafeman, D. M., Merranko, J., Axelson, D., Goldstein, B. I., Goldstein, T., Monk, K., et al. (2016). Toward the definition of a bipolar prodrome: dimensional predictors of bipolar spectrum disorders in at-risk youths. American Journal of Psychiatry, 173(7): 695-704. 
Hans, S.L., Auerbach, J.G., Styr, B., \& Marcus, J. (2004). Offspring of parents with schizophrenia: Mental disorders during childhood and adolescence. Schizophrenia Bulletin, 30 (2): 303-315.

Hartmann, J., Nelson, B., Ratheeth, A., Treen, D., McGorry, P. (2018). At-risk studies and clinical antecedents of psychosis, bipolar disorder and depression: a scoping review in the context of clinical staging. Psychological Medicine, 49: 177-189.

Hartmann, J., Nelson, B.,Spooner, R., Amminger, P., Chanen, A., Davey, C., McHugh, M., Ratheesh, A., Treen, D., Yuen, H.P., McGorry, P. (2017). Broad clinical high-risk mental state (CHARMS): Methodology of a cohort study validating criteria for pluripotent risk. Early Intervention in Psychiatry, 1-8.

Harvey, A. (2008). Sleep and circadian rhythms in bipolar disorder: seeking synchrony, honony and regulation. American Journal of Psychiatry, 165 (7): 820-829.

Harvey, A. G. (2009). A transdiagnostic approach to treating sleep disturbance in psychiatric disorders. Cognitive Behaviour Therapy, 38 (suppl.1), 35-42.

Harvey, A. G. (2016). A transdiagnostic intervention for youth sleep and circadian problems. Cognitive and Behavioral Practice, 23: 341-355.

Hauser, M., \& Correll, C. U. (2013). The significance of at-risk or prodromal symptoms for bipolar I disorder in children and adolescents. Canadian Journal of Psychiatry, 58 (1): 22-31.

Hermans, D., Redoblado Hodge, M., Naismith, S., Kaur, M., Scott, E., Hickie, I. (2011). Neuropsychological clustering highlights cognitive differences in young people presenting with depressive symptoms. Journal Inter Neuropsychol. Soc., 17: 267-276.

Hetrick, S., Cox, G., Merry, S. (2015). Where to go from here? An exploratory meta-analysis of the most promising approaches to depression prevention programs for children and adolescents. International Journal of Environmental research and Public Health, 12: 4758.

Hickie, I., Scott, J., Hermans, D et al., (2013). Clinical classification in mental health at the cross-roads: which direction next? BMC Medicine, 11: 125.

Hill, N., Taylor, L. (2004). Parental school involvement and children’s academic achievement. Current Directions in Psychological Science, 13 (4): 161-164.

Hirschfeld, R., Lewis, L., Vornik, L. (2003). Perceptions and impact of bipolar disorder: how far have we really come? Results of the National Depressive and Manic Depressive Association 2000 Survey of Individuals with Bipolar Disorder. Journal of Clinical Psychiatry, 64 (2): 161-174. 
Hui, C., Morcillo, C., Russo, D., Stochl, J., et al. (2013). Psychiatric morbidity, functioning and quality of life in young people at clinical high risk for psychosis. Schizophr.

Res., 148 (1): 175-180.

Husain, S. A., Allwood, M. A., \& Bell, D. J. (2016). The relationship between PTSD symptoms and attention problems in children exposed to the Bosnian War. Journal of Emotional and Behavioral Disorders, 16, 52-62.

Hutton, P., Bowe, S., Parker, S., Ford, S. (2011). Prevalence of suicide risk factors in people at ultra-high risk of developing psychosis: a service audit. Early Interv. Psychiatry, 5 (4): 375-380.

Hysing, M., Harvey, A., Linton, S., Askeland, K., Sivertsen, B. (2016). Sleep and academic performance in later adolescence: results from a large population-based study. Journal of Sleep Research, 25 (3): 318-324.

International Standard Classification of Education (ISCED). (1975). Division of Statistics on Education, Office of Statistics. Paris: Unesco.

Isohanni I, Jarvelin M, Nieminen P et al. (1998). School performance as a predictor of psychiatric hospitalization in adult life. A 28 year follow up in the Northern Finland 1966 Birth Cohort. Psychol Med, 28 (4): 967-74.

Iyer, S., Boekestyn, L., Cassidy, C., King, S., Joober, R., Malla, A. (2008). Signs and symptoms in the pre-psychotic phase: description and implications for diagnostic trajectories. Psychol Med, 38 (8), 1147-1156.

Jansen, K., Magalhaes, P., Tavares, P., Kapczinski, F., Silva, R. (2012). Early functional impairment in bipolar youth: a nested population based case control study. Journal of Affective Disorders, 43: 208-212.

Jeblenskey A, McGrath J, Herrman $\mathrm{H}$ et al. (1999). People living with psychotic illness: An Australian study 1997-1998. Canberra: Commonwealth of Australia, Department of Health and Aging.

Johansson, R., Carlbring, P., Heedman, A., Paxling, B., Andersson, G. (2013). Depression, anxiety and their comorbidity in the Swedish general population: point prevalence and the effect on health-related quality of life. Peer J, 1: e98.

Johnson E. O., Roth T., Schultz L. and Breslau N. (2006). Epidemiology of DSM-IV insomnia in adolescence: lifetime prevalence, chronicity, and an emergent gender difference. Pediatrics, 117: e247. 
Joo, S., Shin, C., Kim, J., Yi, H., Ahn, Y., Park, M., et al. (2005). Prevalence and correlates of excessive daytime sleepiness in high school students in Korea. Psychiatry Clin Neurosci, 59: 433-440.

Judd, L.L., Schettler, P.J., Solomon, D.A., Maser, J.D., Coryell, W., Endicott, J., Akiskal, H.S. (2008). Psychosocial disability and work role function compared across the long-term course of bipolar I, bipolar II and unipolar major depressive disorders. J. Affect. Disord., 108: 49-58.

Kapczinski, F., Magalhaes, P., Balanza-Martinez, V., Dias, V., Gama, F., Gonzales-Pinto, A., Grande, I., Ha, K et al., (2014). Staging systems in bipolar disorder: an International Society for Bipolar Disorders Task Force Report. Acta Psychiatrica Scandinavica, 130: 354-363.

Kaur-Sant’Anna, M., Kapczinski, F., Andreazza, A., Bond, D., Lam, R., Young, L et al. (2009). Brain-derived neurotrophic factor and inflammatory markers in patients with early vs late stage bipolar disorder. International Journal of Neuropsychopharmacology, 12: 447-458.

Kelleher, I., Keeley, H., Corcoran, P., Lynch, F., et al. (2012). Clinicopathological significance of psychotic experiences in non-psychotic young people: evidence from four population-based studies. Br. J. Psychiatry, 1: 26-32.

Kendler, K., Bulik, C., Silberg, J., Hettema, J., Myers, J., Prescott, C. (2000). Childhood sexual abuse and adult psychiatric and substance use disorders in women: an epidemiological and Cotwin control analysis. Arch Gen Psychiatry, 57(10): 953-9.

Kendler, K. S., \& Eaves, L. J. (Eds.). (2005). Review of psychiatry series, Vol. 24 no. 1. Psychiatric genetics. Arlington, VA, US: American Psychiatric Publishing, Inc.

Kendler, K., O'Donovan, M. (2014). A breakthrough in schizophrenia genetics. Jama Psychiatry, 71: 1319-20.

Keshavan, M., Montrose, D.M., Rajarethinam, R., Diwadkar, V., Prasad, K., \& Sweeney, J.A. (2008). Psychopathology among offspring of parents with schizophrenia: Relationship to premorbid impairments. Schizophrenia Research, 103: 114-120.

Kessing, L. (2004). Severity of depressive episodes according to ICD-10: prediction of risk and relapse and suicide. British Journal of Psychiatry, 184: 153-156.

Kessler, R. (1997). The effects of stressful life events on depression. Annual Review of Psychology, 48: 191-214.

Kessler, R., Amminger, P. (2007). Age of onset of mental disorders: a review of recent literature. Curr Opin Psychiatry, 20 (4): 359-364. 
Kessler, R., Berglund, P., Demler, O., Jin, R., Merikangas, K., Walters, E. (2005). Lifetime prevalence and age-of-onset distributions of DSM-1V disorders in the National Comorbidity Survey Replication. Arch Gen Psychiat, 62 (6): 593-602.

Khan, A., McCormack, H., Bolger, A., et al. (2015). Childhood maltreatment, depression, and suicidal ideation: critical importance of parental and peer emotional abuse during developmental sensitive periods in males and females. Frontiers in Psychiatry, 6 (42): 1-28.

Kira, I. A., Lewandowski, L., Ashby, J. S., Somers, C., Chiodo, L., \& Odenat, L. (2014). Does bullying victimization suppress IQ? The effects of bullying victimization on IQ in Iraqi and African American adolescents: A traumatology perspective. Journal of Aggression, Maltreatment \& Trauma, 23: 431-453.

Kira, I. A., Lewandowski, L., Somers, C. L., Yoon, J. S., \& Chiodo, L. (2012). The effects of trauma types, cumulative trauma, and PTSD on IQ in two highly traumatized adolescent groups. Psychological Trauma: Theory, Research, Practice, and Policy, 4: 128-139.

Kline, E., Seidman, L., Cornblatt, B., Woodberry, K., et al. (2018). Depression and clinical high-risk states: Baseline presentation of depressed vs. non=depressed participants in the NAPLS-2 cohort. Schizophrenia Research, 192: 357-363.

Klosterkötter, J., Hellmich, M., Steinmeyer, E., Schultze-Lutter, F. (2001). Diagnosing schizophrenia in the initial prodromal phase. Arch Gen Psychiatry, 58 (2): 158-164.

Konjarski, M., Murray, G., Lee, V., Jackson, M. (2018). Reciprocal relationships between daily sleep and mood: a systematic review of naturalistic prospective studies. Sleep Medicine Reviews, 42: 47-58.

Kraan, T., Velthorst, E., Smit, F., Haan, L., van der Gaag, M. (2015). Trauma and recent life events in individuals at ultra high risk for psychosis: review and meta-analysis. Schizophrenia Research, 161 (2-3): 143-149.

Kronholm, E., Puusniekka, R., Jokela, J., Villberg, J et al., (2015). Trends in self-reported sleep problems, tiredness and related school performance among Finnish adolescents from 1984 to 2011. Journal of Sleep Research, 24: 3-10.

Kupfer, D., Frank, E., Grochocinski, V., Cluss, P., Houck, P., Stapf, D. (2002). Demographic and clinical characteristics of individuals in a bipolar disorder case registry. J Clin

Psychiatry, 63: 120-125.

Lamers-Winkelman, F., Willemen, A., Visser, M. (2012). Childhood Experiences of referred children exposed to intimate partner violence: consequences for their wellbeing. Child Abuse Negl., 36: 166-179. 
Langeveld, J., Joa, I., Larsen, T., Rennan, J., Cosmovici, E., Johannessen, J. (2011).

Teachers' awareness for psychotic symptoms in secondary school: the effects of an early detection programme and information campaign. Early Intervention in Psychiatry, 5 (2), 115121.

Lansford, J. E., Dodge, K. A., Pettit, G. S., Bates, J. E., Crozier, J., \& Kaplow, J. (2002). A 12-year prospective study of the long-term effects of early child physical maltreatment on psychological, behavioral, and academic problems in adolescence. Archives of Pediatrics and Adolescent Medicine, 156:, 824-830.

Last, C., Hansen, C., Franco, N. (1997). Anxious children in adulthood: a prospective study of adjustment. J Am Acad Child Adolesc Psychiatry, 36: 645-652.

Lazaratou, H.,Dikeos, D., Anagnostopoulos, D., Sbokou, O., Soldatos, C. (2005). Sleep problems in adolescence a study of senior high school students in Greece. Eur Child Adoles Psy, 14: 237-243.

Leach, L., Butterworth, P. (2012). The effect of early onset common mental disorders on educational attainment in Australia. Psychiatric Research, 199 (1): 51-57.

Lee Y. J., Cho S.-J., Cho I. H., Jang J. H. and Kim S. J. (2012). The relationship between psychotic-like experiences and sleep disturbances in adolescents. Sleep Medicine, 13: 10211027.

Leinonen, J.A., Solantaus, T.S., \& Punamaki, R.L. (2003). Parental mental health and children's adjustment: The quality of marital interaction and parenting as mediating factors. Journal of Child Psychology and Psychiatry, 44 (2):, 227-241.

Lemos-Giráldez, S., Vallina-Fernández, O., Fernández-Iglesias, P., Vallejo-Seco, G., et al. (2009). Symptomatic and functional outcome in youth at ultra-high risk for psychosis: a longitudinal study. Schizophr. Res., 115 (2-3): 121-129.

Leschied, A. W., Chiodo, D., Whitehead, P. C., \& Hurley, D. (2005). The relationship between maternal depression and child outcomes in a child welfare sample: Implications for treatment and policy. Child \& Family Social Work, 10: 281-291.

Levenson, J. C., Axelson, D. A., Merranko, J., Angulo, M., Goldstein, T. R., Mullin, B. C., et al. (2015). Differences in sleep disturbances among offspring of parents with and without bipolar disorder: association with conversion to bipolar disorder. Bipolar Disorders, 17 (8): 836-848.

Lewinsohn, P., Hops, H., Roberts, R., Roberts, R., Seeley, S. (1993). Adolescent psychopathology: Prevalence incidence of depression and other DSM-111R disorders in high school studies. J Abnorm Psychol, 102: 110-120. 
Lieb, R., Isensee, B., Hofler, M., Pfister, H., \& Wittchen, H.U. (2002). Parental major depression and the risk of depression and other mental disorders in offspring: A prospectivelongitudinal community study. Archives of General Psychiatry, 59 (4): 365-374.

Lim, J., Rekhi, G., Rapisarda, A., Lam, M., et al. (2015). Impact of psychiatric comorbidity in individuals at Ultra High Risk of psychosis - findings from the Longitudinal Youth at Risk Study (LYRIKS). Schizophr. Res, 164 (1-3): 8-14.

Lin, A., Wood, S.J., Nelson, B., Beavan, A., McGorry, P., Yung, A.R. (2015). Outcomes of no transitioned cases in a sample at ultra-high risk for psychosis. Am. J. Psychiatry, 172 (3): 249-258.

Lin, A., Wood, S., Yung, A. (2013). Measuring psychosocial outcome is good. Curr. Opin. Psychiatry, 26 (2): 138-143.

Lizardi, H., Klein, D.N., \& Shankman, S.A. (2004). Psychopathology in the adolescent and young adult offspring of parents with dysthymic disorder and major depressive disorder. Journal of Nervous and Mental Disease, 192 (3): 193-199.

Loeppke, R., Taitel, M., Haufle, V., Parry, T., Kessler, R., Jinnett, K. (2009). Health and productivity as a business strategy: a multiemployer study. J Occup Environ Med., 51: 411428.

Lucchesi L.M., Pradella-Hallinan M., Lucchesi M., Moraes W.A. (2005). Sleep in psychiatric disorders. Rev Bras Psiquiatr. 27 (Suppl 1): 27-32.

Lunsford-Avery, J. R., Orr, J. M., Gupta, T., Pelletier-Baldelli, A., Dean, D. J., Smith Watts, A. K., ... Mittal, V. A. (2013). Sleep Dysfunction and Thalamic Abnormalities in Adolescents at Ultra High-Risk for Psychosis. Schizophrenia Research, 151: (1-3): 148-153.

MacCabe, J., Lambe, M., Cattinggius, S., Sham, P., David, A., Reichenberg, A et al. (2010). Excellent school performance at age 16 and risk of adult bipolar disorder: National cohort study. British Journal of Psychiatry, 196 (2): 109-115.

Magaud, E., Nyman, K., \& Addington, J. (2013). Cyberbullying in those at Clinical High Risk for psychosis. Early Intervention in Psychiatry, 7(4), 427-430.

Mak, K., Lee, S., Ho, S., Lo, W. et al. (2012). Sleep and academic performance in Hong Kong adolescents. Journal of School Health, 82 (11):, 522-527.

Maquet, P. (1995). Sleep function(s) and cerebral metabolism. Behav. Brain Res., 69 (1): 7583. 
Masia-Warner, C., Nangle, D., Hansen, D. (2006). Bringing evidence-based child mental health services to the schools: General issues and specific populations. Education and treatment of Children, 29: 165-172.

Masillo, A., Monducci, E., Pucci, D., Telesforo, L., Battaglia, C., Carlotto, A., Forte, A., Bonaccorsi, E., Romano, A., Nastro, P., Girardi, P. (2012). Evaluation of secondary school teachers' knowledge about psychosis: a contribution to early detection. Early Intervention in Psychiatry, 6: 76-82.

Maybery, D., Ling, L., Szakacs, E. (2006). Children of a parent with a mental illness: Perspectives on need. Advances in Mental Health, 4 (2): 78-88.

Maybery, D., \& Reupert, A. (2009). Parental mental illness: a review of barriers and issues for working with families and children. Journal of Psychiatric and Mental Health Nursing, 16 (9): 784-791.

Mayo, D., Corey, S., Kelly, L., Yohannes, S., Youngquist, A., Stuart, B., Niendam, T., Loewy, R. (2017). The role of trauma and stressful life events among individuals at clinical high risk of psychosis: a review. Frontiers of Psychiatry, April

https://doi.org/10.3389/fpsyt.2017.00055

Maziade, M., Gingras, N., Rouleau, N., et al. (2008). Clinical diagnoses in young offspring from eastern Québec multigenerational families densely affected by schizophrenia or bipolar disorder. Acta Psychiatr Scand, 117: 118-126.

McAusland, L., Buchy, L., Cadenhead, K., Cannon, T., et al. (2017). Anxiety in Youth at Clinical High Risk for Psychosis. Early Interv. Psychiatry, 11 (6): 480-487.

McFarlane, W., Cook, W., Downing, D. (2010). Portland identification and early referral: a community-based system for identifying and treating youths at high risk of psychosis. Psychiatric Services, 61: 512-515.

McGorry, P. (2007). Issues for DSM-V: clinical staging: a heuristic pathway to valid nosology and safer, more effective treatment in psychiatry. Am J Psychiatry: 164: 859-60.

McGorry, P. (2010). Risk syndromes, clinical staging and DSM V: New diagnostic infrastructure for early intervention in psychiatry. Schizophr Res, 120, 49-53.

McGorry, P., Bates, T., Birchwood, M. (2013). Designing youth mental health services for the 21st century: examples from Australia, Ireland and the UK. Br J Psychiatry, 54 (suppl): s30-35.

McGorry, P., Goldstone, S., Parker, A., Rickwood, D., Hickie, I. (2014). Cultures for mental health care of young people: an Australian blueprint for reform. Lancet Psychiatry, 1: 559_ 68. 
McGorry, P., Hartmann, J., Spooner, R., Nelson, B. (2018). Beyond the “at risk mental state” concept: transitioning to transdiagnostic psychiatry. World Psychiatry, 17: 133-142.

McGorry, P.D., Hickie, I.B., Yung, A.R., Pantelis, C., Jackson, H.J. (2006). Clinical staging of psychiatric disorders: a heuristic framework for choosing earlier, safer and more effective interventions. Aust. N. Z. J. Psychiatry, 40: 616-622.

McGorry, P., Nelson, B. (2016). Why we need a transdiagnostic staging approach to emerging psychopathology, early diagnosis, and treatment. JAMA Psychiatry, 73: 191-92.

McHugh, J., McGorry, P., Yuen, H., Hickie, I., Thompson, A., de Haan, L., Mossaheb, N., Smesny, S et al., (2018). The Ultra-High-Risk for psychosis groups: Evidence to maintain the status quo. Schizophrenia research, 195, 543-548.

McLean, C. P., Rosenbach, S. B., Capaldi, S., \& Foa, E. B. (2013). Social and academic functioning in adolescents with child sexual abuse-related PTSD. Child Abuse and Neglect, 37: 675-678.

Meijer, A., van den Wittenboer, G. (2004). The joint contribution of sleep, intelligence and motivation to school performance. Pers Indiv Differ, 37: 95-106.

Merikangas, K., Ames, M., Cui, L., Stang, P., Ustun, T., Von Korff, M., et al. (2007). The impact of comorbidity of mental and physical conditions on role disability in the US adult household population. Arch Gen Psychiatry, 64: 1180-1188.

Merry, S., Hetrisk, S., Cox, G., Brudevold-Iversen, T., Bir, J., McDowell, H. (2011). Psychological and educational interventions for preventing depression in children and adolescents. Cochrane Database of Systematic Reviews, Cd003380.

Merry, S., Statsiak, K. (2011). Depression in young people. In P. Gluckman \& H. Hayne (Eds.), Improving the transition: Reducing social and psychological morbidity during adolescence: A report from the Prime Minister's Chief Science Advisor (pp. 191-206). Wellington: Office of the Prime Minister's Science Advisory Committee.

Mesman, E., Nolen, W. A., Keijsers, L., \& Hillegers, M. H. J. (2017). Baseline dimensional psychopathology and future mood disorder onset: findings from the Dutch Bipolar Offspring Study. Acta Psychiatrica Scandinavica, 136 (2): 201-209.

Meyer, E., Carrión, R., Cornblatt, B., Addington, J., et al. (2014). The relationship of neurocognition and negative symptoms to social and role functioning over time in individuals at clinical high risk in the first phase of the North American Prodrome Longitudinal Study.

Schizophr. Bull, 40 (6): 1452-1461. 
Miller, T., Zipursky, R., Perkins, D., Addington, J., Woods, S., Hawkins, K. et al. (2003). The PRIME North America randomized double-blind clinical trial of olanzapine versus placebo in patients at risk of being prodromally symptomatic for psychosis. II. Baseline characteristics of the "prodromal” sample. Schizophr Res, 61: 19-30.

Monroe, C., Borzi, M. G., \& Burrell, R. D. (1992). Communication apprehension among high school dropouts. The School Counsellor, 39, 273-280.

Morriss, R., Yang, M., Chopra, A., Bentall, R., Paykall, E., Scott, J. (2013). Differential effects of depression and mania symptoms on social adjustment: prospective study in bipolar disorder. Bipolar Disorders, 15 (1): 80-91.

Muenzenmaier, K., Seixas, A., Schneeberger, A., Castille, D., Battaglia, J., Link, B. (2015). Cumulative effects of stressful childhood experiences on delusions and hallucinations. $J$ Trauma Dissociation, 16 (4): 442-62.

National Statistics and the United Kingdom. (2010). Youth cohort study and the longitudinal study of young people in England: the activities and experiences of 18 year olds in England 2009. National Statistics, Department of Education. United Kingdom.

Nehmy, T., Wade, T. (2014). Reduction in the prospective incidence of adolescent psychopathology: A review of school-based prevention approaches. Mental Health \& Prevention, 2: 66-79.

Nelson, B., Amminger, P., Yuen, HP. (2018). Staged Treatment in Early Psychosis: a sequential multiple assignment randomised trial of interventions for ultra high risk of psychosis patients. Early Intervention in Psychiatry, 12 (3): 292-306.

Nelson, B., Yuen, H.P., Wood, S.J., Lin, A., Spiliotacopoulos, D et al., (2013). Long-term follow-up of a group at ultra high risk ("prodromal”) for psychosis: the PACE 400 study. JAMA Psychiatry, 70 (8): 793-802.

Niemi, L.T., Suvisaari, J.M., Haukka, J.K., Wrede, G., \& Lonnqvist, J.K. (2004). Cumulative incidence of mental disorders among offspring of mothers with psychotic disorder: Results from the Helsinki High-Risk Study. British Journal of Psychiatry, 185 (1): 11-17.

Niendam, T., Bearden, C., Johnson, J., McKinley, M., et al., (2006). Neurocognitive performance and functional disability in the psychosis prodrome. Schizophr. Res., 84 (1): 100-111.

Nieman, D. H., Ruhrmann, S., Dragt, S., Soen, F., van Tricht, M. J., Koelman, J. H., ... de Haan, L. (2014). Psychosis prediction: stratification of risk estimation with informationprocessing and premorbid functioning variables. Schizophrenia bulletin, 40(6), 1482-1490. 
O'Brien, E., Mindell, J. (2005). Sleep and risk-taking behavior in adolescents. Behav Sleep Med, 3: 113-133.

O’Dea, B., Lee, R., McGorry, P., Hickie, I., Scott, J., Pantelis, C., Amminger, P., Glozier, N. (2016). A prospective cohort study of depression course, functional disability and NEET status in help-seeking young adults. Social Psychiatry and Psychiatric Epidemiology, 51: 1395-1404.

Ohayon, M. M., Carskadon, M. A., Guilleminault, C., \& Vitiello, M. V. (2004). Metanalysis of quantitative sleep parameters from childhood to old age in healthy individuals: developing normative sleep values across the human lifespan. Sleep, 27 (7): 1255-1273.

Organisation for Economic Co-operation and Development (OECD). (2012). NEET rates among youth in OECD countries: Percentage of population aged 15-24. OECD Employment Outlook 2012. OECD Publishing.

Overstreet, S., \& Mathews, T. (2011). Challenges associated with exposure to chronic trauma: Using a public health framework to foster resilient outcomes among youth. Psychology in the Schools, 48, 738-754.

Oyserman, D., Mowbray, C., Meares, P., Firminger, K. (2000). Parenting among mothers with serious mental illness. Am J Orthopsychiatry, 70 (3): 296-315.

Pagel, J., Kwiatkowski, C. (2010). Sleep complaints affective school performance at different educational levels. Frontiers in Neurology, 1:1-6.

Park, R.J., Senior, R., \& Stein, A. (2003). The offspring of mothers with eating disorders. European Child \& Adolescent Psychiatry, 12 (Suppl1): i110-i119.

Patel, V., Flisher, A., Hetrick, S., McGorry, P. (2007). Mental health of young people; a global public-health challenge. Lancet, 369: 1302-1313.

Peh, O., Rapisarda, A., Lee, J. (2018). Childhood adversities in people at ultra-high risk (UHR) for psychosis: Systematic review \& meta-analysis. Schizophrenia Bulletin, 44 (Suppl 1): s S270-S271.

Perez-Chada, D., Perez-Lloret, S., Videla, A., Cardinali, D., et al. (2007). Sleep disordered breathing and daytime sleepiness are associated with poor academic performance in teenagers. A study using the Pediatric Daytime Sleepiness Scale (PDSS). Sleep, 30: 16981703.

Perfect et al., 2016). Perfect, M., Turley, M., Carlson, J. S., Yohannan, J., \& Gilles, M. S. (2016). School-related outcomes of traumatic event exposure and traumatic stress symptoms in students: A systematic review of research from 1990 to 2015. School Mental Health. 8

(1): 7-43.

This article is protected by copyright. All rights reserved. 
Perzow, S. E. D., Petrenko, C. L. M., Garrido, E. F., Combs, M. D., Culhane, S. E., \& Taussig, H. N. (2013). Dissociative Symptoms and Academic Functioning in Maltreated Children: A Preliminary Study. Journal of Trauma \& Dissociation : The Official Journal of the International Society for the Study of Dissociation (ISSD), 14(3), 302-311.

Poe, S., Brucato, G., Bruno, N., Arndt, L., et al. (2017). Sleep disturbances in individuals at clinical high risk for psychosis. Psychiatry Research, 249: 240-243.

Polari, A., Lavoie, S., Yuen, H., Amminger, P., Berger, G., Chen, E., deHaan, L., Hartmenn, $\mathrm{J}$ et al., (2018). Clinical trajectories in the ultra-high risk for psychosis population.

Schizophrenia Research, 197: 550-556.

Porche, M., Costello, D., Rosen-Reynoso, M. (2016). Adverse family experiences, child mental health, and educational outcomes for a national sample of students. School Mental Health, 8 (1): 44-60.

Poulin, P., Daoust, M., Forest, G., Stip, E., Godbout, R. (2003). Sleep architecture and its clinical correlates in first episode and neuroleptic-naïve patients with schizophrenia. Schizophr Res., 62: 147-153.

Putnam, F., (2006). The impact of trauma on child development. Juv Fam Court J, 57 (1): 111.

Quintini, G., Martin, J., Martin, S. (2007). The changing nature of the school to work transition process in OECD countries. Institute for the Study of Labour, Germany.

Quiroga C, Morin A, Janosz M, Bisset S. (2013). Early adolescent depression symptoms and school dropout: mediating processes involving self-reported academic competence and achievement. J Educ Psychol, 105 (2): 552-60.

Ranning, A., Laursen, t., Thorup, A., Hjorthoj, C., Nordentoft, M. (2016). Children of parents with serious mental illness: with whom do they grow up? A prospective population-based study. Journal of the American Academy of Child and Adolescent Psychiatry, 55 (11): 953961.

Read, J., van Os, J., Morrison, A., Ross, C. (2005). Childhood trauma, psychosis and schizophrenia: a literature review with theoretical and clinical implications. Acta Psychiatr Scand, 112 (5): 330-50.

Reupert, A., Maybery D., Kowalenko, N. (2013). Children whose parents have a mental illness: prevalence, need and treatment. Med J Aust, 199 (3 Suppl): S7-S9.

Rickwood, D., Mazzer, K., Telford, N., Parker, A., Tanti, C., McGorry, P. (2015). Changes in psychological distress and psychosocial functioning in young people accessing headspace centres for mental health problems. Medical Journal of Australia, 10: 537-543. 
Rickwood, D., Paraskakis, M., Quin, D., Hobbs, N., Ryall, V., Trethowan, J., McGorry, P. (2018). Australia's innovation in youth mental health care: The headspace centre model. Early Intervention in Psychiatry, 13 (1): 159-166.

Rickwood, D., Van Dyke, N., Telford, N. (2013). Innovation in youth mental health services in Australia: common characteristics across the first headspace centre. Early Intervention in Psychiatry, 9 (1): 29-37.

Rietdijk, J., Ising, H., Dragt, S., Klaassen, R., Nieman, D., et al. (2013). Depression and social anxiety in help-seeking patients with an ultrahigh risk for developing psychosis. Psychiatry Research, 209: 309-313.

Riglin L, Frederickson N, Shelton K, Rice F. (2013). A longitudinal study of psychological functioning and academic attainment at the transition to secondary school. J Adolesc, 36 (3): 507-17.

Riglin, L., Petrides, K., Frederickson, N., Rice, F. (2014). The relationship between emotional problems and subsequent school attainment: a meta-analysis. Journal of Adolescence, 37 (4): 335-346.

Ritter, P.S., Marx, C., Lewtschenko, N. et al. (2012). The characteristics of sleep patients with manifest bipolar disorder, subjects at high risk of developing the disease and healthy controls. Journal of Neural Transmission, 119 (10): 1173-1184.

Rao, U., Ryan, N., Birmaher, B. (1995). Unipolar depression in adolescents: clinical outcome in adulthood. Journal of American Academy of Child and Adolescent Psychiatry, 34: 566578.

Roeser, R., Eccles, J., \& Sameroff, A. (2000). School as a Context of Early Adolescents' Academic and Social-Emotional Development: A Summary of Research Findings. The Elementary School Journal, 100 (5): 443-471.

Rosen, J., Miller, T., D'Andrea, J., McGlashan, T., Wood, S. (2006). Comorbid diagnoses in patients meeting criteria for the schizophrenia prodrome. Schizophrenia Research, 85 (1-3): 124-131,

Ruhrmann, S., Schultze- Lutter, F., Salokangas, R., Heinimaa, M., Linszen, D., Dingemans, P. et al. (2010). Prediction of psychosis in adolescents and young adults at high risk: results from the prospective European prediction of psychosis study. Arch Gen Psychiatry, 67, 241-251.

Rutigliano, G., Valmaggia, L., Landi, P., Frascarelli, M., Cappucciati, M., Sear, V., Rocchetti, M., De Micheli, A., Jones, C., Palombini, E., McGuire, P., Fusar-Poli, P. (2016). Persistence or recurrence of non-psychotic comorbid mental disorders associated with 6year poor functional outcomes in patients at ultra high risk for psychosis. J. Affect. 
Disord., 203: 101-110.

Rutter M, Maughan B, Mortimore P, Ouston J, Smith A. (1979). Fifteen thousand hours: secondary schools and their effects on children. London: Open Books.

Şahin, S., Yüksel, C., Güler, J., Karadayı, G., et al. (2013). The history of childhood trauma among individuals with ultra high risk for psychosis is as common as among patients with first-episode schizophrenia. Early Intervention in Psychiatry, 7 (4): 414-420.

Salokangas, R.K., Ruhrmann, S., von Reventlow, H.G., Heinimaa, M et al., (2012). Axis I diagnoses and transition to psychosis in clinical high-risk patients EPOS project: prospective follow-up of 245 clinical high-risk outpatients in four countries. Schizophr. Res. 138 (2-3): 192-197.

Schlosser, D.A., Jacobson, S., Chen, Q., Sugar, C.A., Niendam, T.A., Li, G., Bearden, C.E., Cannon, T.D. (2012). Recovery from an at-risk state: clinical and functional outcomes of putatively prodromal youth who do not develop psychosis. Schizophr. Bull. 38 (6): 1225-1233.

Schoeman, R., Carey, P., \& Seedat, S. (2009). Trauma and posttraumatic stress disorder in South African adolescents: A case-control study of cognitive deficits. The Journal of Nervous and Mental Disease, 197: 244-250.

Scott, J., Hickie, I., McGorry, P. (2012). Pre-emptive psychiatric treatments: pipe dream or a realistic outcome of clinical staging models? Neuropsychiatry, 2: 263-266.

Scott, J., Leboyer, M., Hickie, I., Berk, M., Kapczinski, F., Frank, E., Kupfer, D., McGorry, P. (2013). Clinical staging in psychiatry: a cross-cutting model of diagnosis with heuristic and practical value. The British Journal of Psychiatry, 202: 243-245.

Scott, J., Scott, E., Hermens, D., Naismith, S., Guastella, A., White, D ... Hickie, I. (2014). Functional impairments in adolscents and young adults with emerging mood disoders.

British Journal of Psychiatry, 2005 (5): 362-368.

Seginer, R. (2006). Parents’ educational involvement: A developmental ecological perspective. Parenting Science and Practice, 6 (1): 1-48.

Shonk, S., \& Cicchetti, D. (2001). Maltreatment, competency deficits and risk for academic and behavioural maladjustment. Dev Psychol, 37 (1): 3-17.

Short, M., Louca, M. (2015). Sleep deprivation leads to mood deficits in healthy adolescents. Sleep Medicine, 16 (8): 987-993. 
Simon, G.E., Bauer, M.S., Ludman, E.J., Operskalski, B.H., Unutzer, J. (2007). Mood symptoms, functional impairment, and disability in people with bipolar disorder: specific effects of mania and depression. J. Clin. Psychiatry, 68: 1237-1245.

Simon, G., Ludman, E., Unutzer, J., Operskalski, B., Bauer, M. (2008). Severity of mood symptoms and work productivity in people treated for bipolar disorder. Bipolar Disorders, 10: 718-725.

Simon, A.E., Velthorst, E., Nieman, D.H., Linszen, D., Umbricht, D., de Haan, L. (2011). Ultra high-risk state for psychosis and non-transition: a systematic review. Schizophr. Res., 132: 8-17.

Spinhoven, P., Elzinga, B., Hovens J., et al. (2010). The specificity of childhood adversities and negative life events across the life span to anxiety and depressive disorders. Journal of Affective Disorders, 126 (1-2): 103-112.

Stattin, H., Kerr, M. (2000). Parental monitoring: A reinterpretation. Child Dev, 71 (4): 1072-1085.

Stea, T.H., Knutsen, T., and Torstveit, M.K. (2014). Association between short time in bed, health-risk behaviors and poor academic achievement among Norwegian adolescents. Sleep Med., 15 (6): 666-671.

Stein H, Galletly C, Clark S, Wilson J, Killen E, Anthes L. (2012). Understanding the social costs of psychosis: The experience of adults affected by psychosis identified within the second Australian national survey of psychosis. Aust N Z J Psychiatry 46 (9): 879-889.

Stickgold, R., Hobson, J., Foose, R., Fosse. M. (2001). Sleep, learning, and dreams: off-line memory reprocessing. Science, 294 (5544): 1052-1057.

Stockings, E., Degenhardt, L., Dobbins, T., Lee, Y., Erskine, H., Whiteford, H., Patton, G. (2016). Preventing depression and anxiety in young people: A review of the joint efficiency of universal, selective and indicated prevention. Psychological Medicine, 46: 11-26.

Stowkowy, J., \& Addington, J. (2013). Predictors of a clinical high risk status among individuals with a family history of psychosis. Schizophrenia Research, 147, 281-286.

Suhrcke, M., Arce, R., McKee, M., Rocco, L. (2008). Economic Costs of Ill Health in the European Region. European Observatory on Health Systems and Policies, World Health Organization: Copenhagen, 2008

Svirskis, T., Korkeila, J., Heinimaa, M., Huttunen, J., et al. (2005). Axis 1 disorders and vulnerability to psychosis. Schizophrenia Research, 75 (2-3): 439-446. 
Sweeney, J., Kmiec, J., Kupfer, D. (2000). Neuropsychological impairments in bipolar and unipolar mood disorders on the CANTAB neurocognitive battery. Biological Psychiatry, 48 (7): 674-684.

Tan, H., Ang, Y. (2001). First-episode psychosis in the military: a comparative study of prodromal symptoms. Aust N Z J Psychiatry, 35: 512-519.

Taras, H., Potts-Datema, W. (2015). Sleep and student performance at school. J Sch Health, 75 (7): 248-254.

Tickell, A., Scott, E., Davenport, T., Iorfina, F., Ospina- Pinillios, L., Harel, K., Parker, L., Hickie, I., Hermans, D. (2019). Neurocognitive clusters: A pilot study of young people with affective disorders in an inpatient facility. Journal of Affective Disorders, 242: 80-86.

Thompson, J., Gallagher, P., Hughes, J., Watson, S., Gray, J., Ferrier, I., Young, A. (2005). Neurocognitive impairment in euthymic patients with bipolar affective Disorder. British Journal of Psychiatry, 186: 32-40.

Thompson, J., Kelly, M., Kimhy,D., Harkavy-Friedman, J., Khan, S., et al., (2009). Childhood trauma and prodromal symptoms among individuals at clinical high risk for psychosis. Schizophr. Res., 108 (1-3): 176-181.

Thompson, A., Nelson, B., Yuen, H., Lin, A. (2013). Sexual trauma increases the risk of developing psychosis in an ultra high-risk "prodromal” population. Schizophr. Bull., 40 (3): 697-706.

Thompson, A., Nelson, B., Yung, A. (2011). Predictive validity of clinical variables in the "at risk" for psychosis population: international comparison with results from the North American Prodrome Longitudinal Study. Schizophr. Res., 126 (1-3): 51-57.

Tikka, M., Luutonen, S., Ilonen, T., Tuominen, L., et al., (2013). Childhood trauma and premorbid adjustment among individuals at clinical high risk for psychosis and normal control subjects. Early Interv. Psychiatry, 7 (1): 51-57.

Titova, O.E., Hogenkamp, P.S., Jacobsson, J.A., Feldman, I., Schioth, H.B., and Benedict, C. (2015). Associations of self-reported sleep disturbance and duration with academic failure in community-dwelling Swedish adolescents: sleep and academic performance at school. Sleep Med., 16 (1): 87-93.

Tohen, M., Hennen, J., Zarate, C., Baldessarini, R., Strakowski, S.M., Stoll, A.L., Faedda, G.L., Suppes, T., Gebre-Medhin, P., Cohen, B.M. (2000). The McLean First Episode Project: Two-year syndromal and functional recovery in 219 cases of major affective disorders with psychotic features. Am J Psychiatry, 157: 220-228. 
Trickett, P. K., Kim, K., \& Prindle, J. (2011). Variations in emotional abuse experiences among multiply maltreated young adolescents and relations with developmental outcomes. Child Abuse and Neglect, 35: 876-886.

Tunnard, C., Rane, L., Wooderson, S., Markopoulou, K., Poon, L., Fekadu, A., et al. (2014). The impact of childhood adversity on suicidality and clinical course in treatment-resistant depression. J Affect Disord, 15 (2 ):122-30.

Valmaggia, L., Stahl, D., Yung, A., Nelson, B., et al. (2013). Negative psychotic symptoms and impaired role functioning predict transition outcomes in the at-risk mental state: a latent class cluster analysis study. Psychological Medicine, 43 (11): 2311-2325.

Van Ameringen, M., Mancini, C., Farvolden, P. (2003). The impact of anxiety disorders on educational achievement. Journal of Anxiety Disorder, 17 (5): 561-571.

Vandeleur, C., Rothen, S., Gholam-Rezaee, M., et al. (2012). Mental disorders in offspring of parents with bipolar and major depressive disorders. Bipolar Disord, 14: 641-653.

Van Os, J., Guloksuz, S. (2017). A critique of the "ultra-high risk” and "transition” paradigm. World Psychiatry, 16: 200-206.

Van Zoonen, K., Buntrock, C., Ebert, D., Smit, F., Reynolds, C. (2014). Preventing the onset of major depressive disorder: A meta-analytic review of psychological interventions. International Journal of Epidemiology, 43: 318-329.

Varese, F., Smeets, F., Drukker, M., Lieverse, R., Lataster, T., Viechtbauer, W., et al., (2012). Childhood adversities increase the risk of psychosis: a meta-analysis of patientcontrol, prospective-and cross-sectional cohort studies. Schizophr. Bull., 38 (4): 661-671.

Velthorst, E., Nieman, D.H., Becker, H.E., van de Fliert, R., Dingemans, P et al. (2009). Baseline differences in clinical symptomatology between ultra high risk subjects with and without a transition to psychosis. Schizophr. Res. 109 (1-3): 60-65.

Velthorst, E., Nieman, D., Linszen, D., Becker, H., et al. (2010). Disability in people clinically at high risk of psychosis. Br. J. Psychiatry, 197 (4): 278-284.

Viezel et al., 2015). Viezel, K. D., Freer, B. D., Lowell, A., \& Castillo, J. A. (2015). Cognitive abilities of maltreated children. Psychology in the Schools, 52: 92-106.

Vreeker, A., Boks, M. P., Abramovic, L., Verkooijen, S., van Bergen, A. H., Hillegers, M. H., ... GROUP Investigators (2015). High educational performance is a distinctive feature of bipolar disorder: a study on cognition in bipolar disorder, schizophrenia patients, relatives and controls. Psychological medicine, 46 (4), 807-818.

Waghorn G, Saha S, Harvey C, Morgan V, Waterreus A, Bush R ... McGrath 
J. (2012). 'Earning and learning' in those with psychotic disorders: The second Australian national survey of psychosis. Aust N Z J Psychiatry, 46 (8):774-785.

Wang, M. T., \& Eccles, J. S. (2012). Social support matters: longitudinal effects of social support on three dimensions of school engagement from middle to high school. Child Development, 83: 877-895.

Wang, T., Sheikh-Khalil, S. (2014). Does parental involvement matter for student achievement and mental health in high school? Child Dev, 85 (2): 610-625.

Warner-Seidler, A., Perry, Y., Calear, A., Newby, J., Christense, H. (2017). School-based depression and anxiety prevention programs for young people: A systematic review and meta-analysis. Clinical Psychology Review, 51: 30-47.

Weissman, M.M., Wickramaratne, P., Nomura, Y., Warner, V., Pilowsky, D., \& Verdeli, H. (2006). Offspring of depressed parents: 20 years later. American Journal of Psychiatry, 163 (6): 1001-1008.

Weldman, A., Augustine, A., Murayama, K., Elliot, A. (2015). Internalizing symptomatology and academic achievement: bi-directional prospective relations in adolescence. Journal of Research in Personality, 58: 106-114.

Widom, C., DuMont, K., Czaja, S. (2007). A prospective investigation of major depressive disorder and comorbidity in abused and neglected children grown up. Archives of General Psychiatry, 64(1): 49-56.

Wigman, J., van Nierop, M., Vollebergh, W., Lieb, R., et al. (2012). Evidence that psychotic symptoms are prevalent in disorders of anxiety and depression, impacting on illness onset, risk, and severity-implications for diagnosis and ultra-high risk research. Schizophr. Bull, 38 (2): 247-257.

Wolfson, A., Carskadon, M. (2003). Understanding adolescents' sleep patterns and school performance: a critical appraisal. Sleep Med Rev, 7: 491-506.

Wong, M. M., Brower, K. J., \& Zucker, R. A. (2011). Sleep problems, suicidal ideation, and self-harm behaviors in adolescence. Journal of psychiatric research, 45(4), 505-511.

Woodbridge, M., Sumi, C., Thornton, P., Fabrikant, N., et al. (2016). Screening for trauma in early adolescence: Findings from a diverse school district. School Mental Health, 8 (1): 89-105.

Woods, S.W., Addington, J., Cadenhead, K.S., Cannon, T.D. (2009). Validity of the prodromal risk syndrome for first psychosis: findings from the north American Prodrome longitudinal study. Schizophr. Bull. 35 (5), 894-908. 
Wulff, K., Dijk, D., Middleton, B., Foster, R., \& Joyce, E. (2012). Sleep and circadian rhythm disruption in schizophrenia. British Journal of Psychiatry, 200(4), 308-316.

Yang, C., Kim, J., Patel, S., Lee, J. (2005). Age-related changes in sleep/wake patterns among Korean teenagers. Pediatrics, 111 (1): 250-256.

Young, M., Harford, K., Kinder, B., Savell, J. (2007). The relationship between childhood sexual abuse and adult mental health among undergraduates: victim gender doesn't matter. $J$ Interpers Violence, 22 (10): 1315-31.

Yung, A. R. (2017). Treatment of people at ultra-high risk for psychosis. World Psychiatry, 16 (2): 207-208.

Yung, A. R., Buckby, J. A., Cotton, S. M., Cosgrave, E. M., Killackey, E. J., Stanford, C., ... McGorry, P. D. (2005). Psychotic-like experiences in nonpsychotic help-seekers: associations with distress, depression, and disability. Schizophrenia bulletin, 32(2), 352-359.

Yung A., Cotter, J., Wood, S. (2015). Childhood maltreatment and transition to psychotic disorder independently predict long-term functioning in young people at ultra- high risk for psychosis. Psychol Med, 45: 3453-65.

Yung, A., McGorry. P. (1996). The initial prodrome in psychosis: descriptive and qualitative aspects. Aust N Z J Psychiatry, 30: 587-599.

Yung, A., Phillips, L., Yeun, H., McGorry, P. (2004). Risk factors for psychosis in an ultra high risk group: psychopathology and clinical features. Schizophrenia Research, 67: 131-142.

Yung, A., Woods, S.W., Ruhrmann, S., Addington, J., Schultze-Lutter, F., Cornblatt, A., Amminger, G.P., Bechdolf, A., Birchwood, M., Borgwardt, S., Cannon, T.D. (2012). Whither the attenuated psychosis syndrome? Schizophr. Bull., 38: 1130-1134.

Yung, A., Yuen, H., Berger, G., Francey, S., Hung, T. (2007). Declining transition rate in ultra high risk (prodromal) services: dilution or reduction of risk? Schizophr Bull., 33 (3), 673-81.

Zanini, M., Castro, J., Coelho, F., Bittencourt, L., Bressan, R., Tufik, S. et al. (2013). Do sleep abnormalities and misaligned sleep/circadian rhythm patterns represent early clinical characteristics for developing psychosis in high risk populations? Neurosci Biobehav Rev., 37: 2631-2637.

Ziermans, T., de Wit, S., Schothorst, P., Sprong, M., et al. (2014). Neurocognitive and clinical predictors of long-term outcome in adolescents at ultra-high risk for psychosis: a 6year follow-up. PLoS One, 9 (4): e93994. 


\section{University Library}

\section{- M M I N E R VA \\ A gateway to Melbourne's research publications}

Minerva Access is the Institutional Repository of The University of Melbourne

Author/s:

Bowman, S;McKinstry, C;Howie, L;McGorry, P

Title:

Expanding the search for emerging mental ill health to safeguard student potential and vocational success in high school: A narrative review

Date:

2020-02-05

\section{Citation:}

Bowman, S., McKinstry, C., Howie, L. \& McGorry, P. (2020). Expanding the search for emerging mental ill health to safeguard student potential and vocational success in high school: A narrative review. EARLY INTERVENTION IN PSYCHIATRY, 14 (6), pp.655-676. https://doi.org/10.1111/eip.12928.

Persistent Link:

http://hdl.handle.net/11343/275370 